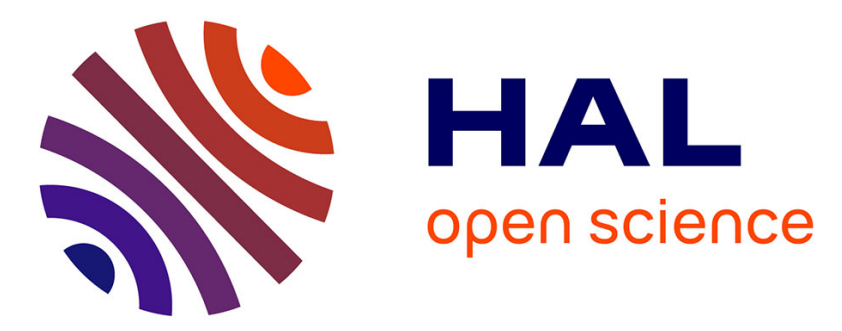

\title{
Testing the performance of dendroclimatic process-based models at global scale with the PAGES2k tree-ring width database
}

Jeanne Rezsöhazy, Fabio Gennaretti, Hugues Goosse, Joël Guiot

\section{- To cite this version:}

Jeanne Rezsöhazy, Fabio Gennaretti, Hugues Goosse, Joël Guiot. Testing the performance of dendroclimatic process-based models at global scale with the PAGES2k tree-ring width database. Climate Dynamics, 2021, 10.1007/s00382-021-05789-7 . hal-03252700

\section{HAL Id: hal-03252700 https://hal.science/hal-03252700}

Submitted on 8 Jun 2021

HAL is a multi-disciplinary open access archive for the deposit and dissemination of scientific research documents, whether they are published or not. The documents may come from teaching and research institutions in France or abroad, or from public or private research centers.
L'archive ouverte pluridisciplinaire HAL, est destinée au dépôt et à la diffusion de documents scientifiques de niveau recherche, publiés ou non, émanant des établissements d'enseignement et de recherche français ou étrangers, des laboratoires publics ou privés. 


\title{
Testing the performance of dendroclimatic process-based models at global scale with the PAGES2k tree-ring width database
}

\author{
Jeanne Rezsöhazy • Fabio Gennaretti • \\ Hugues Goosse · Joël Guiot
}

Received: date / Accepted: date

\begin{abstract}
Tree-rings are one of the most commonly used proxies for reconstructing past climates at annual resolution. The climate information is generally deduced from tree-rings using statistical relationships, but the assumed linearity and stationarity may be inadequate. Process-based models allow for non-stationarity and non-linearity; however, many challenges are associated with their application for global scale reconstructions. In this study, we aim to test the feasibility of using the mechanistic model MAIDEN at the global scale for paleoclimate data assimilation based reconstructions by applying it to the PAGES2k tree-ring width database. We also compare its performance with the simpler model VS-Lite, often used in global applications. Both models are skillful in terms of calibration and verification correlations for a similar number of sites (63 and 64 for VS-Lite and MAIDEN, respectively). VS-Lite 13 tends to perform better for sites where the climate signal in tree-rings is strong 14 and clear. By contrast, MAIDEN's performance is likely mostly limited by the
\end{abstract}

J. Rezsöhazy

Université catholique de Louvain (UCLouvain), Earth and Life Institute (ELI), Georges Lemaître Centre for Earth and Climate Research (TECLIM), Place Louis Pasteur, B-1348 Louvain-la-Neuve, Belgium

Aix Marseille University, CNRS, IRD, INRA, College de France, CEREGE, Aix-en-Provence, France

Tel.: +3210479258

E-mail: jeanne.rezsohazy@uclouvain.be

F. Gennaretti

Institut de recherche sur les forêts, UQAT, Amos, Québec, J9T 2L8, Canada

H. Goosse

Université catholique de Louvain (UCLouvain), Earth and Life Institute (ELI), Georges Lemaître Centre for Earth and Climate Research (TECLIM), Place Louis Pasteur, B-1348 Louvain-la-Neuve, Belgium

J. Guiot

Aix Marseille University, CNRS, IRD, INRA, College de France, CEREGE, Aix-en-Provence, France 
lack of data (for example, daily Gross Primary Production data or phenological timings) needed to accurately calibrate the model. However, when the calibration is robust, both models reproduce well the observed link between climate and tree-growth. In general, VS-Lite tends to overestimate the climate signal in tree-rings compared to MAIDEN, which better reproduces the magnitude of the climate signal on average. Our results show that both models are complementary and can be applied at the global scale to reconstruct past climates using an adequate protocol designed to exploit existing tree-ring data.

Keywords Ecophysiological modelling · Proxy system models · Dendroclimatology · PAGES2k tree-ring database · Paleoclimate data assimilation based reconstructions

\section{Introduction}

Studying past climates prior to the instrumental period requires the use of indirect records of climate variations from natural archives, commonly referred to as proxies (Jones et al., 2009). Different projects and consortia have emerged in recent years to improve global climate reconstructions using the development of global multi-proxy databases spanning last millennium (PAGES 2k Consortium, 2013. Wilson et al., 2016, Anchukaitis et al., 2017, PAGES 2k Consortium, 2017, Tardif et al., 2019, Konecky et al., 2020). Among available records, tree-rings are one of the most commonly used proxies for reconstructing past climates at high temporal (annual) resolution, due to their large spatial coverage and availability (Fritts, 1976, Jones et al., 2009, Mann et al. 2009; Wilson et al., 2016; Anchukaitis et al., 2017; Esper et al., 2018; Anderson et al. 2019; St. George and Esper, 2019).

To make the link between climate and indirect observations of paleoclimate variations from proxies, proxy system models (PSMs; i.e. models that simulate the development of measured variables, for example tree-ring width, in response to a climate forcing; Evans et al., 2013, Dee et al., 2016) must be used. Such models can be applied in the forward mode, for example to compare proxy data directly with climate model simulations when these simulations are used as inputs of the PSM. In the inverse mode, PSMs can reconstruct the climate variations that produce the measured variables (Guiot et al., 2000 Evans et al., 2013).

In the case of tree-growth proxy data (such as tree-ring width, hereafter TRW, or density), the climate information is generally deduced on the basis of a statistical relationship calibrated over the instrumental period (Fritts 1976, Cook and Kairiukstis, 1990, Fritts, 1991, Jones et al., 1998, Mann et al. 1999, 2008). Therefore, many climate reconstructions of the period covered by dendroclimatic data have been developed with linear regressions between climate variables and proxy records (Fritts, 1991; Jones et al., 1998, Mann et al. 1999, 2008). This raises concern about the assumed linearity and stationarity of the relationship deduced from the calibration (Briffa et al., 1998; Wilson and Elling, 2004, Wilson et al., 2007, D'Arrigo et al., 2008, Guiot et al., 2014). A 
complementary approach that has been expanded over the past decade is data assimilation, which combines information from the physics of the system included in climate models and indirect climate observations provided by proxy data, such as TRW (e.g. Goosse et al., 2012; Franke et al., 2017; Steiger et al. 2018, Tardif et al., 2019). So far, the studies using tree-ring proxy data with data assimilation have focused on the use of statistical PSMs (i.e., univariate or multiple linear regressions) to provide a large-scale reconstruction over the past millennia (e.g. Tardif et al. 2019).

As a complement to statistical methods, the link between climate and tree-ring proxy data can be established from process-based PSMs. Mechanistic modelling of tree-growth dependency on climate explicitly states the processes that govern the relationship between climate and tree-growth and allows for non-stationarity and non-linearity (Guiot et al., 2014). While in regressionbased PSMs, tree-growth is assumed to be only dependent on the chosen climate target variables, mechanistic modelling introduces the influence of other climate variables, for example atmospheric $\mathrm{CO}_{2}$ concentration. Additionally, tree-ring-based reconstructions are often limited to sites where tree-growth is driven by one limiting climatic factor. Yet, process-based tree-growth models are able to extract a climate signal from tree-rings at sites where tree-growth is driven by multiple climatic factors. Accordingly, they may expand the area of dendroclimatic reconstructions to a wide range of regions away from extreme growth environments (Breitenmoser et al., 2014, Babst et al., 2018). To date, such models have only been used for local reconstructions (e.g. Boucher et al. 2014). While global scale reconstructions are theoretically possible with a data assimilation procedure including a process-based PSM, such models have only been applied in a pseudo-proxy context (Dee et al., 2016, Acevedo et al., 2017. Steiger and Smerdon, 2017). A further step would be to introduce such mechanistic models in the data assimilation procedure using actual proxy data to possibly improve the quality of the reconstruction.

However, many challenges are associated with the use of process-based tree-ring PSMs for global scale reconstructions. In particular, the inclusion of complex biological processes, for example photosynthesis and carbon allocation, usually implies a cautious initialization and calibration of the model at each particular site of interest, depending on the site environment or the tree species. This information is not readily available at global coverage with the necessary detail. Running and calibration time of such models can also be an obstacle to their utilization.

Among the many available process-based dendroclimatic models, the VaganovShashkin-Lite model (VS-Lite; Tolwinski-Ward et al., 2011) has been used in several paleoclimate studies (Breitenmoser et al., 2014; Lavergne et al., 2015, Dee et al., 2016, Steiger and Smerdon, 2017; Seftigen et al., 2018, Fang and Li, 2019). The model is not considered as fully mechanistic. Indeed, VS-Lite does not include any explicit representation of tree-growth processes, but relies instead on the principle of limiting factors (soil moisture and temperature; Tolwinski-Ward et al. 2011) to mimic the response of tree-ring growth to climate conditions. The model has faced difficulties in simulating tree-growth 
where the dependence on climate is not dominated by a limiting factor, such as precipitation or temperature (Breitenmoser et al., 2014).

Process-based dendroclimatic models that describe more mechanistically the response of proxy data to climate could overcome those limitations. Among the complex mechanistic models (e.g. Misson, 2004, Dufrêne et al., 2005 Vaganov et al., 2006, Drew et al. 2010), we will focus here on the model MAIDEN (Modelling and Analysis In DENdroecology; Misson, 2004) that explicitly includes biological processes and has the potential to be applied at the global scale. Unlike VS-Lite, MAIDEN also takes into account atmospheric $\mathrm{CO}_{2}$ concentration as an input, allowing the user to consider the nonstationary dependency of tree-growth on the recent exponential increase of $\mathrm{CO}_{2}$ (Myhre et al. 2013; Boucher et al., 2014). Another important difference between MAIDEN and VS-Lite is the theoretical basis of the models. VS-Lite is a "sink" model in the sense that it only considers the climate constraints on tree-rings (the carbon sink tissues at the tree-level; see Körner, 2015; Fatichi et al. 2014, 2019). MAIDEN is a "source-sink" mechanistic model in the sense that it first determines the carbon availability by modelling photosynthesis, and second, it allocates the available carbon to the sink tissues based on allocation and climate-dependent rules. Feedbacks between allocation and photosynthesis are also considered in MAIDEN. So far, MAIDEN has been applied to the European temperate forests (Misson, 2004, Boucher et al. 2014), to the Mediterranean forests (Gea-Izquierdo et al., 2015, 2017), to the eastern Canadian taiga (Gennaretti et al., 2017) and to Argentine forests (Lavergne et al., 2017). However, unlike VS-Lite, MAIDEN has not been applied at the global scale yet, due to its level of complexity. In particular, the need for daily climate data at high spatial resolution and for measurements of ecophysiological variables to calibrate the model parameters represents the main limitation for its systematic application in different regions. In Rezsöhazy et al. (2020), a protocol has been developed to calibrate and apply MAIDEN automatically at any site globally that contains TRW observations in the extratropical regions.

To date, the new protocol applying MAIDEN globally has not been demonstrated. To this end, this study highlights the advantages and potential limitations of using a process-based model like MAIDEN at the global scale. In the future, such mechanistic PSM could be utilized for paleoclimate data assimilation based reconstructions. Specifically, we perform a comparative analysis of the performance of the simpler VS-Lite and the more complex MAIDEN process-based models. Both models have been applied over the last century to the global TRW data network of PAGES2k (PAGES 2k Consortium, 2017), including 354 TRW records. Studies such as this which lend insight into the mechanisms controlling tree-ring width and tree-growth elevate our ability to extract meaningful climate information from tree-ring networks. This information is required to improve our understanding of natural and forced decadal climate variability, and to potentially improve reconstructions of past climate variability.

First, we describe MAIDEN and VS-Lite in Sect. 2.1, as well as the TRW data network (Sect. 2.2 and climate data (Sect. 2.3) used in this study. 
The calibration (Sect. 2.4) and verification 2.5 procedure of both models is then presented. The models are calibrated and applied to the PAGES2k TRW database in Sect. 3.1. We provide explanations on the performance of the models in Sect. 3.2. The ability of MAIDEN and VS-Lite to reproduce the climate signal in tree-rings is then evaluated in Sect. 3.3 and, finally, the implications of including atmospheric $\mathrm{CO}_{2}$ concentration as an input of MAIDEN are assessed in Sect. 3.4.

\section{Material and Methods}

\subsection{Tree-growth models}

\subsubsection{MAIDEN}

MAIDEN (Misson, 2004, Gea-Izquierdo et al., 2015, Gennaretti et al., 2017) is a complex tree-growth model that explicitly includes biological processes (photosynthesis and carbon allocation to different tree compartments) to simulate, among other outputs, the annual quantity of carbon allocated to the stem. This key variable is hereafter referred to as Dstem, in grams of carbon per square meter of stand per year. In this study, Dstem is assumed to be proportional to tree-ring growth so as to compare it with TRW observations. The model runs on a daily basis with maximum and minimum air temperature, cumulative precipitation and atmospheric $\mathrm{CO}_{2}$ concentration as inputs.

In this study, we use a combined version of the model from Gea-Izquierdo et al. (2015) (initially developed for Mediterranean forests; hereafter GI2015) and Gennaretti et al. (2017) (initially developed for boreal tree species; hereafter Ge2017) developed by Fabio Gennaretti (unpublished) that gives the possibility to switch between those two versions. The versions from GI2015 and Ge2017 only differ in some mechanistic rules used in the photosynthetic and allocation modules, but they are identical otherwise. The structure of the MAIDEN model is provided online (https://figshare.com/articles/ MAIDEN_ecophysiological_forest_model/5446435/1, last access: 16 May 2020) and its modules are available upon request.

The model includes constants to describe the conditions at the tree-ring observations site and the climate station (Table S1). As in Rezsöhazy et al. (2020), the constants are derived from observations. However, slope and aspect constants are set to zero, as we do not have the field knowledge needed to extract the information from a Digital Elevation Model. MAIDEN includes a four-layer soil module $(1-15 \mathrm{~cm} ; 15-30 \mathrm{~cm} ; 30-65 \mathrm{~cm} ; 65-100 \mathrm{~cm})$ for which we have to provide the main characteristics (clay and sand fractions; Table S1). The soil characteristics are obtained from the Harmonized World Soil Database (hereafter HWSD) v1.2 at a 30 arc-second spatial resolution (FAO/IIASA/ISRIC/ISSCAS/JRC, 2012), as in Rezsöhazy et al. (2020). 
The Vaganov-Shashkin Lite model (Tolwinski-Ward et al., 2011) is a simple tree-growth model that simulates a unitless annual tree-growth increment based on latitude, monthly cumulative precipitation and average temperature of the study site as inputs. It is based on the limiting factors principle (temperature and soil moisture) and on the use of threshold growth response functions. VS-Lite is derived from the full process-based Vaganov-Shashkin model (Vaganov et al., 2006) that has been developed to explicitly quantify the influence of climate and environmental variables on tree-ring formation. While the full model is a two-block model, i.e. a block with cell growth, division and multiplication in the cambium and a growth block based on the limiting factor principle, the Lite version just uses the second block.

\subsection{PAGES2k tree-ring width data}

The PAGES2k working group aims to reconstruct the climate of the last two millennia based on proxy records (PAGES 2k Consortium, 2017). Their community database contains 692 temperature-sensitive proxy records from different archives (trees, ice, sediment, coral, speleothems, documentary evidence, and other archives), among which 354 TRW time series are of interest for our work (PAGES 2k Consortium, 2017). We were able to retrieve the species information needed to run MAIDEN at 307 sites. Time series ending before 1979 were excluded to allow for a long enough calibration period (at least 30 years starting from 1950, Sect. 2.4, leaving 302 TRW time series for our analysis (Fig. 1). The resulting TRW network covers a large range of environmental conditions and tree species (evergreen and deciduous), but is mostly located in the Northern Hemisphere, specifically in North America and Asia. As a consequence, the TRW network is dominated by cold and dry sites (Fig. S1). The tree-ring proxy records in the PAGES2k database have been specifically selected for their local sensitivity to temperature (PAGES 2k Consortium. 2017). However, correlations with other environmental variables can be significant as well, for example with precipitation, and a gradient of environmental sensitivity is thus obtained (water limited sites, temperature limited sites or unclear limiting factor). This can be illustrated by the comparison of the correlations of TRW observations with annual cumulative precipitation against the correlations with mean annual temperature over 1901-2000 (Fig. S2). A wide range of values in the correlations is observed with both variables, with the mean being slightly higher for temperature (0.07 mean correlation, compared to 0.05 for precipitation). TRW data are available online (PAGES 2k Consortium, 2017). 


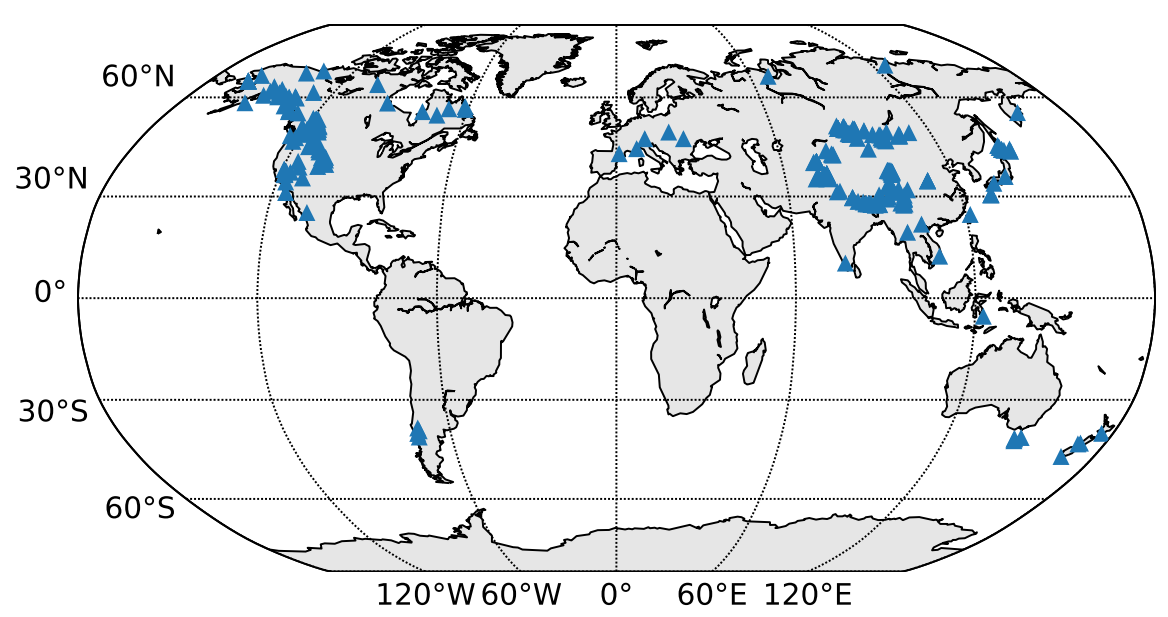

Fig. 1 PAGES2k (PAGES 2k Consortium, 2017) tree-ring width sites used in this study (302 sites). Background map from Hunter (2007).

\subsection{Climate data}

Daily climatic inputs are needed to run MAIDEN (Sect. 2.1.1) while VSLite needs monthly climate inputs (Sect. 2.1.2). In this study, we use the Global Meteorological Forcing Dataset for land surface modelling (v2) (http: //hydrology.princeton.edu/data.php, last access: 13 March 2020; Sheffield et al. 2006) at $0.5^{\circ}$ resolution over the 1901-1949 and 1950-2000 time periods. Daily maximum and minimum temperature and daily cumulative precipitation were extracted for MAIDEN from the grid cell closest to each individual site. Daily mean temperature and cumulative precipitation were averaged and summed, respectively, for VS-Lite at a monthly time step. Annual atmospheric $\mathrm{CO}_{2}$ concentration data are from Sato and Schmidt (https: //data.giss.nasa.gov/modelforce/ghgases/, last access: 6 January 2020) and were linearly interpolated at a daily time step. Note that for the Southern Hemisphere climate data start in July instead of January to match the seasonality of tree-growth.

\subsection{Calibration}

\subsubsection{MAIDEN}

A protocol has been developed in Rezsöhazy et al. (2020) to calibrate MAIDEN in a systematic and automatic way following a Bayesian procedure with Markov Chain Monte Carlo sampling using the DREAMzs algorithm (Hartig et al., 2019). Because we are working with the two versions of MAIDEN here (GeaIzquierdo et al., 2015, Gennaretti et al., 2017), the procedure has been adapted 
to the version from Gea-Izquierdo et al. (2015), that was not used in Rezsöhazy et al. (2020). The Bayesian procedure allows for calibration of the most sensitive parameters of the model. This includes parameters influencing the simulated stand growth primary production or GPP (6 parameters in the Ge2017 version and 5 parameters in the GI2015 version) and parameters influencing the simulated daily quantity of carbon allocated to different tree compartments (12 parameters in the Ge2017 version and 13 parameters in the GI2015 version). Those parameters are referenced hereafter as photosynthesis and carbon allocation parameters, respectively. The calibration starts from prior distributions, assumed to be uniform over an acceptable range, to produce posteriors for each of the 18 calibrated parameters. It is based on the comparison between the normalized (i.e. with a null mean and a standard deviation of 1) simulated annual quantity of carbon allocated to the stem or Dstem and normalized observed TRW time series. Tables S2 and S3 give the definition of each calibrated parameter for both versions. The ranges of the parameters are available for both versions in Tables S4 and S5.

Ideally, photosynthesis parameters should be calibrated by comparing simulated against observed GPP instead of simulated Dstem against observed TRW and prior ranges would have been more informative for each species or biome (Misson, 2004, Danis et al., 2012, Gea-Izquierdo et al., 2015, 2017 Gennaretti et al., 2017, Lavergne et al., 2017). However, this is not possible here as the information is lacking for the majority of sites. Furthermore, the tree-growth index simulated by MAIDEN, which is derived from the annual quantity of carbon allocated to the stem, is not directly comparable to TRW without standardization. We are thus unable to both calibrate the variance and evaluate the error variance of tree-growth (Rezsöhazy et al. 2020). Information is thus missing to guide the Bayesian calibration towards a biologically plausible set of parameters. For example, we miss information to properly constrain phenology. Consequently, the selection of parameters for our simulations has been slightly updated compared to Rezsöhazy et al. (2020). The set of photosynthesis parameters with the highest posterior (Maximum a posteriori value or MAP; Hartig et al., 2019) is selected as in Rezsöhazy et al. (2020). The carbon allocation parameters are then calibrated as in Rezsöhazy et al. (2020). In addition, after the calibration procedure, the model is iteratively run over the top $10 \%$ carbon allocation parameters. The photosynthesis parameters are fixed at their calibrated values. To avoid unrealistic growth period lengths, a parameter set which simulates a growth period of less than 20 days for each year of the calibration period (hereafter, phenological criterion) is excluded. At the end of the iterations, we keep the set of parameters with the highest likelihood. Note that if none of the parameter sets meet the phenological criterion, the MAIDEN calibration is considered as non-valid for this site with the forcing used.

MAIDEN was calibrated at the TRW sites with at least 30 TRW observations available over the 1950-2000 period, using the climate data described in Sect.2.3. For simplicity, the calibration period will be referred to as 1950-2000. 
The Bayesian approach proposed in Tolwinski-Ward et al. (2013) was used to calibrate the four VS-Lite parameters linked to the growth response (lower and upper temperature and soil moisture thresholds of the model; $\mathrm{T}_{1}$ and $\mathrm{T}_{2}$, and $\mathrm{M}_{1}$ and $\mathrm{M}_{2}$, respectively, in Tolwinski-Ward et al. 2011). This Bayesian approach is based on a standard Markov Chain Monte Carlo method to sample the posterior distribution, i.e., a Metropolis-Hastings algorithm embedded within a Gibbs sampler. Default values were given to the other parameters (six soil moisture parameters and two integration window parameters) as provided in the standard version of the model code (https://www.ncei.noaa. gov/pub/data/paleo/softlib/vs-lite/, last access: 16 March 2021).

VS-Lite was optimized at the 302 TRW sites over the same time period as MAIDEN and using the climate dataset described in Sect. 2.3.

\subsection{Verification}

Both models were tested over the 1901-1949 time period, with the same climate data as described in Sect. 2.3 Models were run over the verification period using the parameters calibrated over the 1950-2000 time period as in Sect. 2.4. Pearson correlation coefficients and their corresponding confidence levels were calculated at each site between simulated tree-ring indexes from MAIDEN or VS-Lite and observed TRW on both the calibration and the verification time periods.

\section{Results}

Section 3.1 assesses and compares the general performance of both VS-Lite and MAIDEN models with respect to calibration (Sect. 2.4) and independent verification (Sect. 2.5), in order to determine the sites with the best performance. Section 3.2 explains the performance of both models, by focusing on its relationship with different environmental characteristics, such as climate and tree leaf traits. Section 3.3 evaluates the ability of both PSMs to reproduce the climate signal recorded in tree-rings, and then their potential for paleoclimate data assimilation based reconstructions. Finally, Section 3.4 assesses the effect of $\mathrm{CO}_{2}$ concentration in the MAIDEN model with a sensitivity analysis.

\subsection{Applying MAIDEN and VS-Lite to the PAGES2k TRW sites}

Substantial challenges arose in the calibration of MAIDEN. In particular, at some sites, we were unable to properly set phenology due to the lack of information available for calibration (Sect. 2.4.1). From all 302 calibration experiments (Sect. 2.4.1), 113 sites for Ge2017 and 142 sites for GI2015 were excluded based on the phenological criterion (Sect. 2.4.1). The remaining sites (189 sites for 
Ge2017 and 160 sites for GI2015) will be referred to as MAIDEN selected sites. All the analyses for MAIDEN are performed on these selected sites. From all calibration (Sect. 2.4.1) and verification (Sect. 2.5) experiments for both versions (Gea-Izquierdo et al., 2015, Gennaretti et al., 2017) of MAIDEN (Figs. $\mathrm{S} 3$ - S6), we consider a site as well-fitted only if the following conditions are fulfilled, whatever the model version used: (i) a significant (at the $95 \%$ confidence level) calibration (1950-2000) and verification (1901-1949) correlation $\geq 0.3$; (ii) a growth period length of at least 20 days for each year of the calibration (Sect. 2.4.1) and verification period. If conditions are fulfilled for both versions, the version leading to the highest verification correlation at the site is kept. Based on these criteria, we retained 64 well-fitted sites (Fig. 2a).

For VS-Lite (Sect. 2.4.2 and 2.5 Figs. S7 and S8), the condition for retaining a site is also to have a significant (at the $95 \%$ confidence level) calibration (1950-2000) and verification (1901-1949) correlation $\geq 0.3$. As for MAIDEN, VS-Lite simulated time series were checked for consistency as correlation is not able to account for all artefacts in simulated chronologies. Two sites were considered as invalid since estimated tree-growth indexes were found constant (no growth) for more than 10 successive years. Based on these criteria, we retained 63 well-fitted sites (Fig. 2b).

Considering the loss of correlation from calibration to verification, VS-Lite appears more stable than MAIDEN (Fig. 33 see Fig. S9 for by-site correlations). Calibrating MAIDEN at the global scale without overfitting is indeed a challenge. The mean calibration and mean verification correlations for MAIDEN are 0.68 (with a standard deviation of 0.10 ) and $0.43(0.10)$ respectively, and $0.49(0.14)$ and $0.43(0.11)$ for VS-Lite. 18 well-fitted sites are in common between VS-Lite and MAIDEN (Fig. 4). On average, verification correlations are 0.47 for MAIDEN and 0.48 for VS-Lite with a standard deviation of 0.10 and 0.14 respectively. MAIDEN and VS-Lite are skillful at a similar number of mostly different sites, spread all over the globe. The reasons behind their performance are consequently also different and will be addressed in the next section. However, at the common sites, their respective performances are equivalent. 

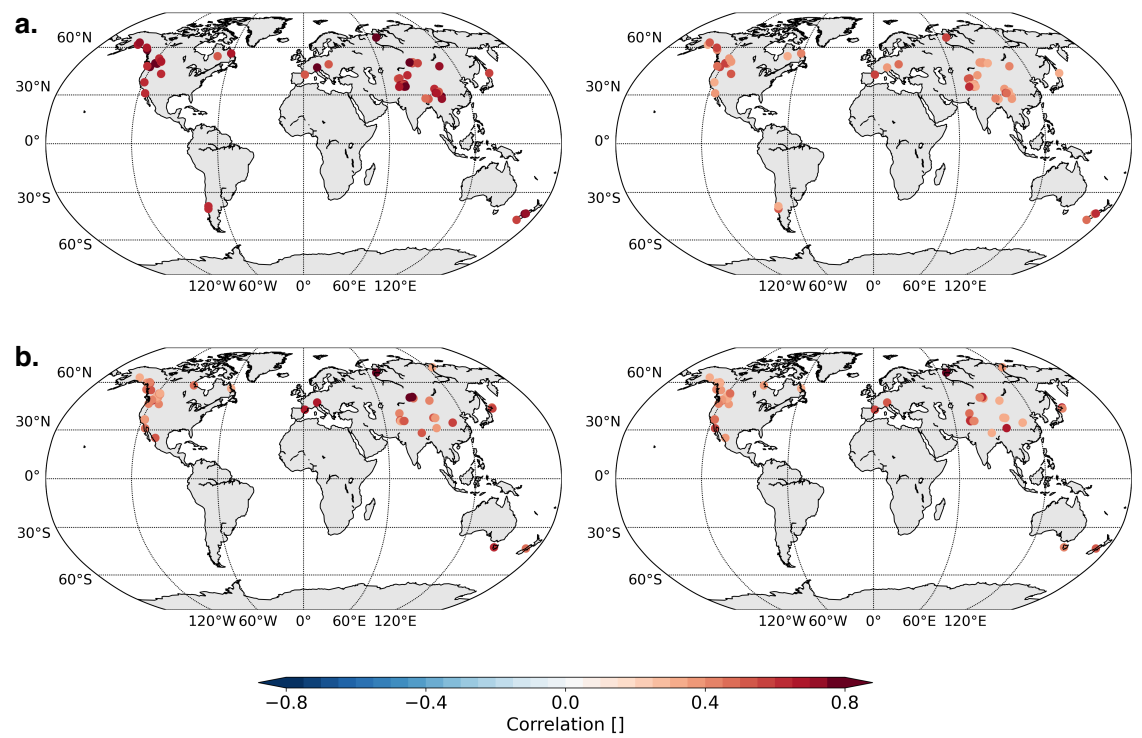

Fig. 2 (a) MAIDEN (64 sites) and (b) VS-Lite (63 sites) calibration (left) and verification (right) correlations for well-fitted sites (Sect. 3.1). All correlations are significant at the $95 \%$ confidence level. Background maps from Hunter (2007).
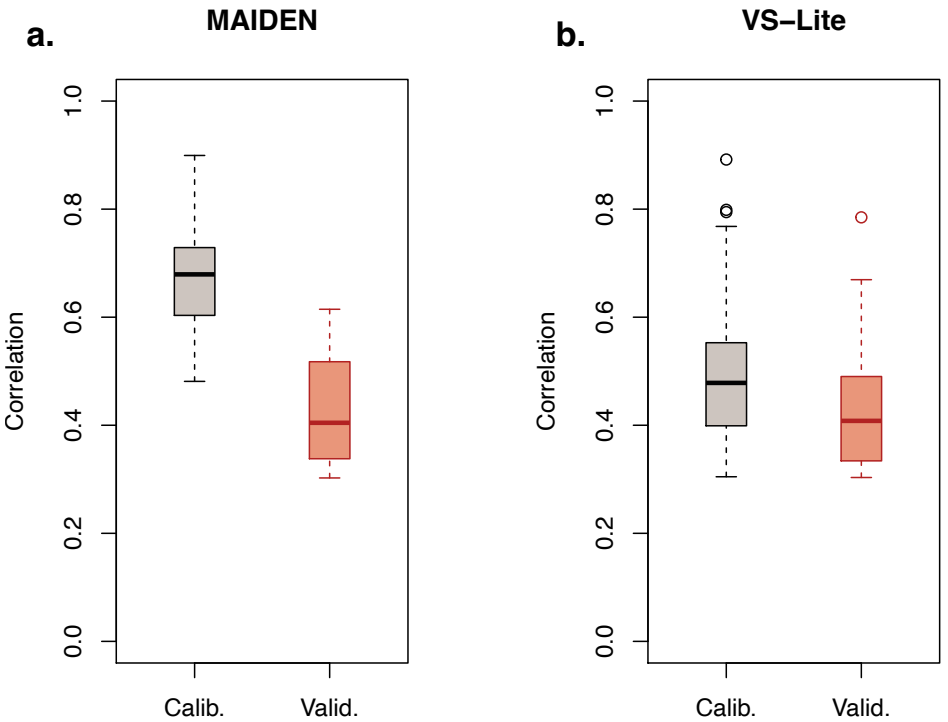

Fig. 3 (a) MAIDEN (64 sites) and (b) VS-Lite (63 sites) calibration (1950-2000) and verification (1901-1949) correlations (all significant at the $95 \%$ confidence level) boxplots for well-fitted sites (Sect. 3.1. 


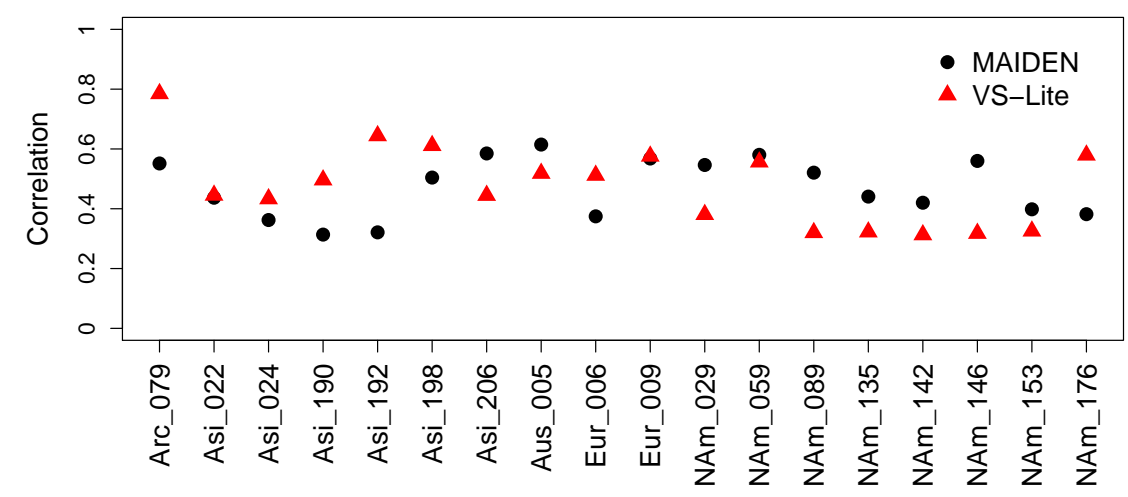

Fig. 4 MAIDEN and VS-Lite verification (1901-1949) correlations (all significant at the $95 \%$ confidence level) for common well-fitted sites (Sect. 3.1) (18 sites, with names from the PAGES2k database: NAm for North American sites; Asi for Asian sites; Eur for European sites; Arc for Arctic sites; Aus for Australian, Tasmanian or New Zealand sites; SAm for South American sites).

\subsection{Explaining the performance of VS-Lite and MAIDEN}

In this section, we want to understand the underlying factors driving the performance of both models. We focus on two site characteristics: tree leaf traits and climate. The relationship between models performance and altitude, latitude or calibration period length (ranging from 30 to 51 years) was also checked but none of these variables were found to be a significant driver of models skill. We are here considering all calibrated sites (Sect. 2.4), irrespective of whether they were identified as well-fitted in the previous section or not.

Verification correlations as a function of tree leaf traits (deciduous or evergreen) are shown on Fig. 5 for both versions of MAIDEN and for VS-Lite. VS-Lite performance (Fig. 5F) does not seem to be influenced by leaf trait, with an average correlation of 0.184 and 0.221 for deciduous and evergreen trees respectively. 13 sites out of 63 well-fitted sites are deciduous which is comparable to the proportion of deciduous sites in the PAGES2k TRW database (64 deciduous out of 302 sites, i.e. around 20\%). For MAIDEN (Fig. 5a and b), verification correlations are also very close on average for deciduous (0.073 for GI2015 and 0.101 for Ge2017) and evergreen trees (0.087 for GI2015 and 0.113 for Ge2017). However, there is a low proportion of deciduous trees for Ge2017 (Fig. 5p) that passes the phenological criterion for the calibration described in Sect. 2.4.1 (9 out of 64 sites) compared to evergreen trees (180 out of 238 sites). Conversely, this proportion is far higher for GI2015 (36 sites out of 64 ; Fig. 5 a) and comparable to evergreen trees (124 sites out of 238). Besides, seven sites out of 64 well-fitted sites are deciduous which is less than the proportion of deciduous sites in the PAGES2k TRW database (64 out of 302 
sites). Only one deciduous well-fitted site is simulated by Ge2017, and six by GI2015. A possible reason is that only the version from Gea-Izquierdo et al. (2015) has already been applied to deciduous trees sites (Quercus Pyrenaica; Gea-Izquierdo et al. 2017). Consequently, we were able to use the initialization parameters already applied to deciduous trees in this version solely. The version from Gennaretti et al. (2017) has never been specifically calibrated for deciduous trees and some initialization parameters are likely not adapted in that case. This exemplifies the fact that the calibration and initialization of MAIDEN are probably the main obstacles for a better performance of the model at the global scale.

To study the influence of climate on the performance of both models, we focus on different climate indicators: cumulative October to September precipitation, annual mean temperature and mean July-August-September temperature. In general, correlations of climate indicators with verification scores at all sites are low and not significant for both VS-Lite and MAIDEN (Table S6). This means that the performance of both models does not depend primarily on the mean climate at a site. Another hypothesis to test is whether the models perform better for sites where tree-ring growth is strongly controlled by climate. To this end, we compare the correlations between climate variables and observed TRW to the verification correlations (Table 1). Since none of the correlations in Table 1 are significant ( $\mathrm{p}$-value $<0.05)$ for MAIDEN, its performance does not rely significantly on tree-growth correlation with climate. On the contrary, VS-Lite performance shows a higher dependency on tree-growth correlation with climate, especially temperature (Table 1). Indeed, all correlations between the tree-growth relationship with climate and verification scores for VS-Lite are significant and particularly high for annual (0.467) and July-August-September (0.506) temperature. We obtain the same result for VS-Lite when the analysis is restricted to the MAIDEN selected sites (Sect. 2.4.1) (Table S7). This dependence of VS-Lite performance to the presence of a strong climate driver of tree-growth is consistent with what has been highlighted in Breitenmoser et al. (2014). It is likely due to the structure of VS-Lite on itself (Sect. 2.1.2), as tree-growth directly depends on the identified limiting climatic factor (temperature or soil moisture) at the site in the model. VS-Lite tends to be better where tree-growth is predominantly driven by climate, which can be limiting for its application in many regions of the world away from the treeline environments (for example high-altitude or high-latitude environments), often not considered for paleoclimate reconstruction (Breitenmoser et al., 2014; Babst et al., 2018). Conversely, in MAIDEN, multiple biological processes shape the links that exist between climate and tree-growth. This potentially brings a better suitability of MAIDEN to work in a larger range of environments than VS-Lite, where the relationship between climate and tree-growth is more complex. 

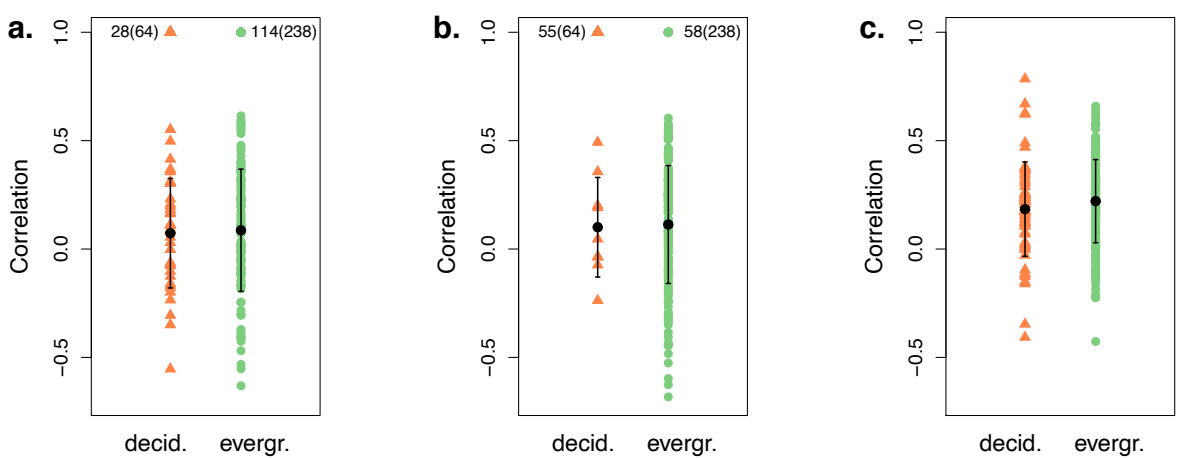

Fig. 5 Verification correlations, mean and standard deviation by tree types (deciduous or evergreen) for the MAIDEN version of GI2015 (a) and Ge2017 (b), for selected sites (160 sites for GI2015 and 189 for Ge2017, Sect. 2.4.1 others have been put to 1; the number of sites that have been put to 1 is indicated by category with the total number of sites in each category in brackets) and VS-Lite, for all 302 sites (c).

Table 1 Pearson correlations between correlations of observed TRW with different climate indicators and MAIDEN or VS-Lite verification correlations (1901-1949). O-S stands for the year starting from October (previous year) to September (current year); P for precipitation; JAS for July-August-September; $\mathrm{T}$ for temperature. Asterisks stand for significant correlations ( $p$-value $<0.05$ ). The difference in the number of sites on which correlations are computed is due to the phenological criterion that has been applied to MAIDEN calibrated sites (see Sect. 2.4.1 for more details).

\begin{tabular}{ll}
\hline Model (version) & Correlation \\
\hline Correlations between observed TRW and O-S P correlation and & \\
verification correlation & 0.114 \\
MAIDEN (Ge2017; 189 sites) & 0.155 \\
MAIDEN (GI2015; 160 sites) & $0.149^{*}$ \\
$\quad$ VS-Lite ( 302 sites) & \\
Correlations between observed TRW and annual T correlation and & \\
verification correlation & 0.074 \\
MAIDEN (Ge2017; 189 sites) & 0.059 \\
MAIDEN (GI2015; 160 sites) & $0.467^{*}$ \\
$\quad$ VS-Lite (302 sites) & \\
Correlations between observed TRW and JAS T correlation and & -0.039 \\
verification correlation & -0.097 \\
MAIDEN (Ge2017; 189 sites) & $0.506^{*}$ \\
MAIDEN (GI2015; 160 sites) & \\
\hline VS-Lite (302 sites)
\end{tabular}

3.3 Assessing the ability of MAIDEN and VS-Lite to reproduce climate relationship with tree-growth

One of the ultimate purposes of PSMs like VS-Lite and MAIDEN is to be used to reconstruct past climates, for example by including them in a data 
assimilation procedure (Evans et al., 2013, Dee et al., 2016). Therefore, we have to assess if these models are able to reproduce well the climate signal recorded in TRW. In the previous section, we established if the models ability to reproduce tree-growth depends on the presence of a strong climate signal recorded in the tree rings. In this section, we want to evaluate if the simulated climate signal, whatever its predominance, is consistent with its recording by tree-ring indexes. This is based on the comparison of the correlations of different climate indicators with tree-growth in simulations and in observations: firstly, by means of scatterplots (Figs. 6, 77 and 8) and secondly, by means of correlations (Table 2).

For MAIDEN (Figs. 6 and 7), over- and underestimations of the climate dependencies of tree-growth are more balanced than for VS-Lite (Fig. 8) as the dots in the scatterplots tend to spread more equally around and are closer to the 1:1 line, particularly for temperature. Conversely, the scatterplots of VS-Lite (Fig. 8) show a stronger overestimation of the climate dependency of tree-growth at most sites, as most of the dots are far above the diagonal. This bias is particularly large for temperature. Indeed, for VS-Lite, the correlation for mean annual temperature is overestimated by more than 0.4 at $43 \%$ of the sites (12\% for GI2015 and $18 \%$ for Ge2017), at $47 \%$ of the sites for mean July-August-September temperature (7\% for GI2015 and 13\% for Ge2017), and at $28 \%$ of the sites for October-September cumulative precipitation (17\% for GI2015 and 12\% for Ge2017). The same conclusion is still valid for VS-Lite when we restrict the analysis to the MAIDEN selected sites (Sect. 2.4.1) (Figs. S10-S15). This overestimation of the climate signal enhanced by the model is a crucial feature to consider when using such PSMs in paleoclimatology, as it can lead to biased climate reconstruction. Again, the structure of VS-Lite is likely responsible for the overestimation of the climate influence on treegrowth as tree-growth is not driven by any other internal or external drivers than limiting climatic factors. The very high correlations $(r>0.7)$ between the VS-lite simulations and basic climate indicators on Fig. 8 at many sites indicate the simplicity of the climate dependence of tree-growth in this PSM. In MAIDEN, many biological processes are in play to frame the climate dependence of tree-growth. MAIDEN uses different functional rules specific to the ongoing phenological phase to allocate at a daily time step the available carbon from photosynthesis and stored non-structural carbohydrates to different tree compartments. The functional rules directly depend on climate factors, such as growing degree days, soil water content or temperature, and are specific to the phenological phase. Simultaneaously, the daily photosynthesis is simulated following the biochemical model of Farquhar et al. (1980) and dynamically interacts with the allocation module. The combination and interaction of these processes may smooth out the direct climate signal on tree-ring growth.

Correlations between observed and simulated (MAIDEN or VS-Lite) treegrowth dependency on climate at all sites are generally low (ranging from 0.053 to 0.515 ), particularly for temperature, even if mostly significant (Table 2). The correlations for VS-Lite when we restrict the analysis to the MAIDEN selected sites (Sect. 2.4.1) are in Table S8 and are similar to the results for 
all 302 sites. In other words, when considering all sites, both models have low skill in reproducing correctly the actual climate signal observed in tree-rings. However the well-fitted sites (Sect. 3.1) have better correlations, ranging from 0.648 (annual temperature) to 0.759 (July-August-September temperature) for MAIDEN and 0.678 (annual temperature) to 0.837 (October-September precipitation) for VS-Lite. Both models are thus able to accurately mimic the climate signal in tree-ring observations if the sites are carefully selected (Sect. 3.1). When focusing on the common well-fitted sites between VS-Lite and MAIDEN, VS-Lite is slightly better at reproducing climate, specifically for annual temperature (0.608 correlation for MAIDEN and 0.772 for VS-Lite) and precipitation (0.747 for MAIDEN and 0.886 for VS-Lite).
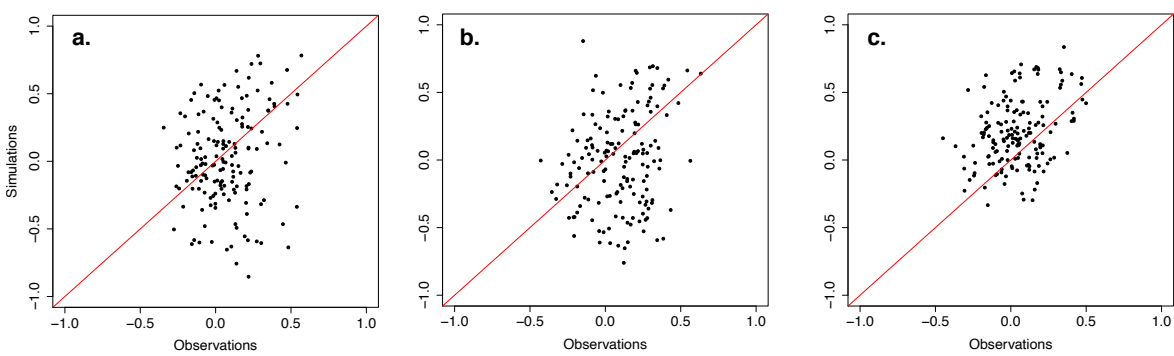

Fig. 6 Correlations between mean annual temperature (a), mean July-August-September temperature (b), October-September cumulative precipitation (c) and MAIDEN (GI2015) Dstem simulations as a function of correlations between the same climate indicators and TRW observations for selected sites (160 out of 302 sites; Sect. 2.4.1) over the 1901-1949 verification period.
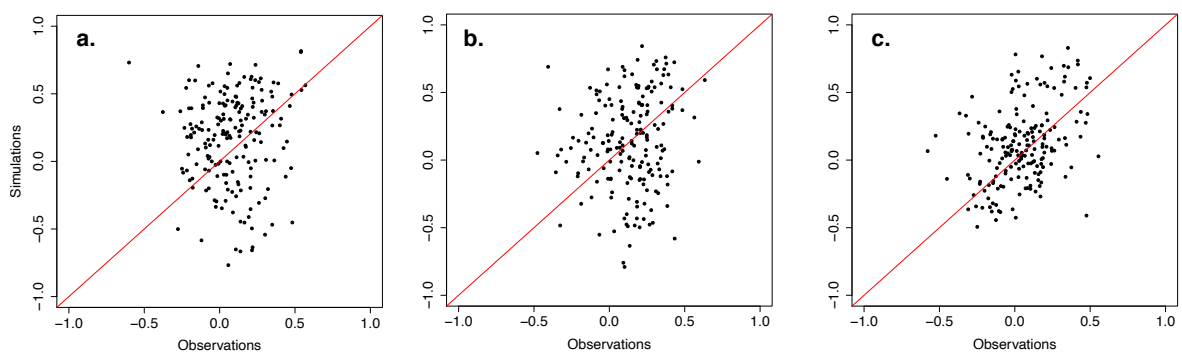

Fig. 7 Correlations between mean annual temperature (a), mean July-August-September temperature (b), October-September cumulative precipitation (c) and MAIDEN (Ge2017) Dstem simulations as a function of correlations between the same climate indicators and TRW observations for selected sites (189 out of 302 sites; Sect. 2.4.1) over the 1901-1949 verification period. 

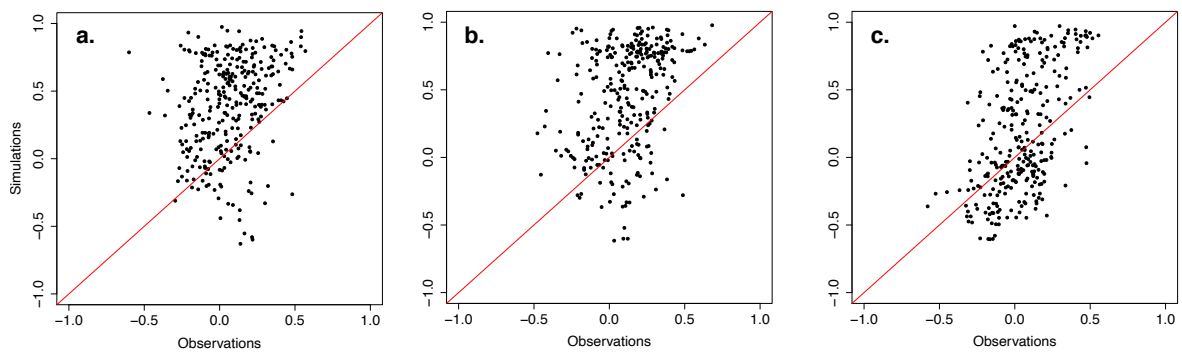

Fig. 8 Correlations between mean annual temperature (a), mean July-August-September temperature (middle), October-September cumulative precipitation (b) and VS-Lite treering index simulations as a function of correlations between the same climate indicators and TRW observations for all sites (302) over the 1901-1949 verification period.

Table 2 Pearson correlations of correlations between different climate indicators and treering width observations with correlations between the same climate indicators and MAIDEN or VS-Lite tree-growth simulations (1901-1949 verification period). O-S stands for the year starting from October (previous year) to September (current year); P for precipitation; JAS for July-August-September; $\mathrm{T}$ for temperature; TRindex for tree-ring index. Asterisks stand for significant correlations ( $\mathrm{p}$-value $<0.05$ ). The difference in the number of sites on which correlations are computed is due to the phenological criterion that has been applied to MAIDEN calibrated sites (see Sect.2.4.1 for more details).

\begin{tabular}{ll}
\hline Model (version) & Correlation \\
\hline Correlations between observed TRW and O-S P correlation and & \\
simulated TRindex and O-S P correlation & $0.388^{*}$ \\
MAIDEN (Ge2017; 189 sites) & $0.322^{*}$ \\
MAIDEN (GI2015; 160 sites) & $0.515^{*}$ \\
VS-Lite (302 sites) & $0.694^{*}$ \\
MAIDEN (well-fitted sites only) & $0.837^{*}$ \\
VS-Lite (well-fitted sites only) & $0.747^{*}$ \\
MAIDEN (common well-fitted sites only) & $0.886^{*}$ \\
VS-Lite (common well-fitted sites only) & \\
Correlations between observed TRW and annual T correlation and & \\
simulated TRindex and annual T correlation & 0.053 \\
MAIDEN (Ge2017; 189 sites) & $0.171^{*}$ \\
MAIDEN (GI2015; 160 sites) & $0.241^{*}$ \\
VS-Lite (302 sites) & $0.648^{*}$ \\
MAIDEN (well-fitted sites only) & $0.678^{*}$ \\
VS-Lite (well-fitted sites only) & $0.608^{*}$ \\
MAIDEN (common well-fitted sites only) & $0.772^{*}$ \\
VS-Lite (common well-fitted sites only) & \\
Correlations between observed TRW and JAS T correlation and & \\
simulated TRindex and JAS T correlation & 0.130 \\
MAIDEN (Ge2017; 189 sites) & $0.216^{*}$ \\
MAIDEN (GI2015; 160 sites) & $0.338^{*}$ \\
VS-Lite (302 sites) & $0.759^{*}$ \\
MAIDEN (well-fitted sites only) & $0.704^{*}$ \\
VS-Lite (well-fitted sites only) & $0.739^{*}$ \\
MAIDEN (common well-fitted sites only) & $0.787^{*}$ \\
VS-Lite (common well-fitted sites only) &
\end{tabular}


3.4 Sensitivity analysis of MAIDEN to atmospheric $\mathrm{CO}_{2}$ concentration

In this section, we perform a sensitivity analysis of the MAIDEN model to atmospheric $\mathrm{CO}_{2}$ concentration. The $\mathrm{CO}_{2}$ concentration is a key driver of the forest carbon fluxes but its actual effects are still difficult to consider and evaluate in dendroecological studies (Körner et al., 2005, Silva et al., 2010. Peñuelas et al., 2011, Lévesque et al., 2014, Van Der Sleen et al., 2015; Girardin et al. , 2016, Hararuk et al., 2019, Giguère-Croteau et al., 2019, Marchand et al., 2020). Yet, the $\mathrm{CO}_{2}$ concentration has increased by $30 \%$ over the last 50 years and might increase up to $1000 \mathrm{ppm}$ at the 2100 horizon (RCP 8.5; Myhre et al., 2013) relative to the current $414.49 \mathrm{ppm}$ (December 2020, https:// www.esrl.noaa.gov/gmd/ccgg/trends/global.html, last access: 19 March 2021), which will have an impact on the forest carbon fluxes. This effect should be taken into account in dendroecological analysis (Babst et al. 2018). In MAIDEN, the $\mathrm{CO}_{2}$ influences the forest carbon fluxes through the coupled modelling of photosynthesis and stomatal conductance (Farquhar et al., 1980 Leuning, 1995) with environmental dependencies related to temperature and soil water content (Gea-Izquierdo et al., 2015, Gennaretti et al., 2017), and the feedbacks between the coupled photosynthesis-stomatal conductance system and the carbon allocation.

Here, we evaluate the influence of the inclusion of the $\mathrm{CO}_{2}$ concentration increase in MAIDEN by comparing its performance in the standard configuration with a sensitivity experiment in which the $\mathrm{CO}_{2}$ concentration is kept constant, for the 64 well-fitted sites (Sect. 3.1), with parameters calibrated based on the $\mathrm{CO}_{2}$ increasing scenario. The $\mathrm{CO}_{2}$ is fixed at its 1st January 1980 value for the Northern Hemisphere (339 ppm), and at its 1st July 1980 value for the Southern Hemisphere (340 ppm).

At each site, we computed the difference between normalized MAIDEN tree-ring growth simulations and normalized TRW observations from 1990 with increasing $\mathrm{CO}_{2}$ and constant $\mathrm{CO}_{2}$. We performed our analysis on the 60 sites out of 64 well-fitted sites that end at least in 1990. Note that both simulations were normalized over 1950-2000 based on the mean and standard deviation of the original simulation, i.e. with increasing $\mathrm{CO}_{2}$, over the same time period. The density distributions of the difference for both experiments are shown on Fig. 9 a. The Pearson's Chi-squared test indicates a significant difference between the two experiments distributions ( $\mathrm{p}$-value $<0.05$ ). The mean for both experiments are -0.209 and 0.182 for the constant $\mathrm{CO}_{2}$ and increasing $\mathrm{CO}_{2}$ experiment, respectively. In other words, while not taking into account $\mathrm{CO}_{2}$ tends to underestimate the actual tree-growth on average, taking into account the increase of $\mathrm{CO}_{2}$ in MAIDEN leads to overestimate it. Ecophysiological models are indeed known to overestimate the actual effect of $\mathrm{CO}_{2}$ (Peñuelas et al., 2011, Gea-Izquierdo et al., 2017). However, the $\mathrm{CO}_{2}$ concentration has certainly an impact on the tree carbon assimilation (Marchand et al., 2020) that should be properly considered to avoid potential biases in climate and growth trend reconstructions derived from tree-ring data. This impact can be taken into account by ecophysiological models such as MAIDEN, but potential 
overestimations must be carefully envisaged due to the generic default of such models.

The trend of simulated and observed tree-growth was also computed and compared at each of the 60 sites. It corresponds to the coefficient of regression of the normalized tree-growth simulations or observations from 1970 up to 1990 at least, versus the years. The simulated trend by MAIDEN may reproduce the generally positive trend that is observed from 1970 in TRW time series (Fig. $9 \mathrm{p}$ ) in correlation with the increasing $\mathrm{CO}_{2}$ concentrations.

Consequently, our results show that the growth trends simulated by MAIDEN are significantly influenced by the $\mathrm{CO}_{2}$ increase and that MAIDEN simulated tree-growth is closer to the observed TRW when including the $\mathrm{CO}_{2}$ concentration increase. This limited analysis is not sufficient to draw conclusions regarding $\mathrm{CO}_{2}$ fertilization in trees but it highlights a potential $\mathrm{CO}_{2}$ effect based on a model that takes into account a commonly used biochemical formulation of photosynthesis (Farquhar et al., 1980). Including the effect of $\mathrm{CO}_{2}$ in a mechanistic model like MAIDEN is a potential advantage over statistical and simple process-based models such as VS-Lite that are not able to account for these processes strongly influencing the forest carbon fluxes. However, because of the remaining uncertainties on the associated processes, an improved representation of the effect of $\mathrm{CO}_{2}$ in process-based dendroecological models is needed to analyse past and future growth trends and variability.

a.

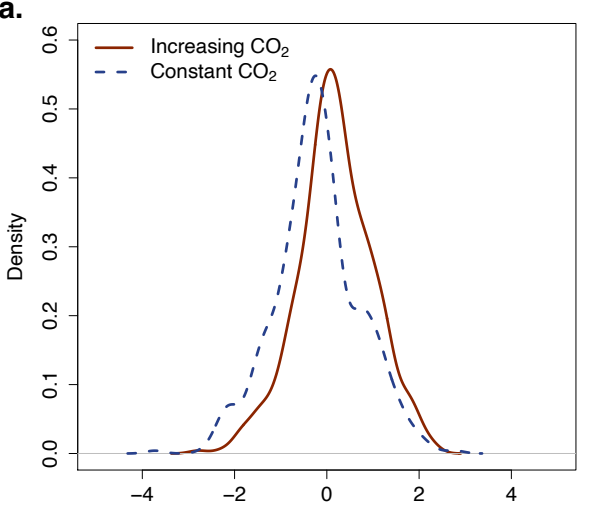

b.

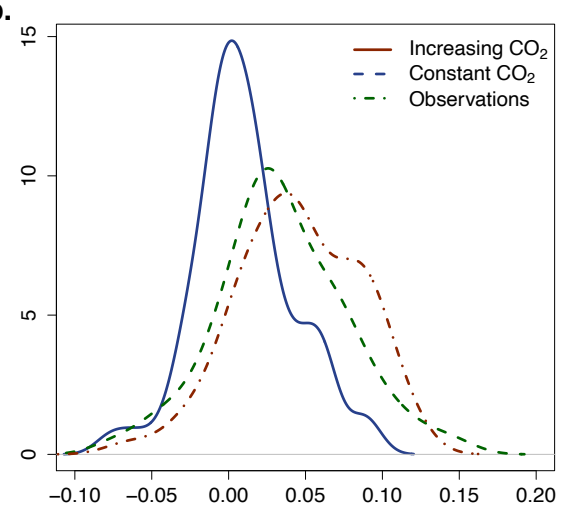

Fig. 9 Density distributions of (a) the difference between normalized tree-ring index simulations by MAIDEN and observed tree-ring width from 1990 with increasing $\mathrm{CO}_{2}$ concentration (in red, i.e. the original configuration), and constant $\mathrm{CO}_{2}$ concentration (in blue); (b) the trend from 1970 of normalized tree-ring index simulations by MAIDEN with increasing $\mathrm{CO}_{2}$ concentration (in red, i.e. the original configuration) or with constant $\mathrm{CO}_{2}$ concentration (in blue), and of normalized tree-ring width observations (in green); at 60 out of 64 well-fitted sites (Sect. 3.1. 


\section{Discussion and conclusions}

In this paper, we have applied and compared two dendroclimatic processbased models of different complexity levels, VS-Lite and MAIDEN, using the global PAGES2k TRW database over the last century. We have evaluated their respective abilities and advantages to be used at the global scale as PSMs for paleoclimate data assimilation based reconstructions.

The models appear to be skillful for a similar number of mostly different sites (63 sites for VS-Lite and 64 sites for MAIDEN, 18 sites in common), spread over all continents. The performance of the models is comparable in terms of calibration and verification correlations. VS-Lite generally results in more stable correlations between the calibration and verification periods. When focusing on the factors that can drive the performance of both models, VS-Lite displays a strong correlation between its verification scores and tree-growth correlations with temperature, while MAIDEN does not. This means that VS-Lite tends to perform better at sites where observed treegrowth strongly correlates with temperature. In other words, the model's performance is improved in environments characterized by extreme temperatures. This feature hampers its application in many regions of the world away from the treeline, already rarely considered for paleoclimate reconstruction. In contrast, MAIDEN performance is less sensitive to the climate signal in TRW time series. We presume that MAIDEN performance is mainly limited by the lack of information needed to accurately calibrate and initialize the model at each specific site. As mentioned above, the information needed to calibrate MAIDEN is a key limitation of complex tree-growth models in general for use at a broader scale. This lack of data (for example, the observed Gross Primary Productivity data) also hinders a complete evaluation and identification of the factors driving the performance of MAIDEN.

At the sites where each model works well in terms of calibration and verification correlations, both VS-Lite and MAIDEN are on average able to successfully retrieve the climate signal in tree-rings. A careful selection of the tree-ring sites provides the opportunity to focus on the most robust simulated relationship between climate and tree-growth. However, VS-Lite appears to predominantly overestimate the observed dependence of tree-growth on climate, while there is no systematic bias for MAIDEN. The overestimation of the climate signal recorded in tree-rings has to be carefully taken into account when using such tree-growth models for data assimilation based reconstructions as it can result in biases. This is a clear disadvantage when using less complex dendroclimatic models, such as VS-Lite, in which the climate and tree-growth relationship is simplified.

Consequently, we may recommend using MAIDEN especially when the relationship between climate and tree-growth is complex with interacting limiting factors. VS-Lite would be a good candidate if tree-growth is mostly limited by only one climatic factor (e.g. summer temperature), although it may overestimate these climate dependences, particularly for temperature, leading to overconfident reconstructions. In this case, MAIDEN should produce more 
plausible results. However, if not enough data are available to properly set and calibrate MAIDEN (for example long daily climate data or soil characteristics), VS-Lite should be preferred. As shown in Rezsöhazy et al. (2020), MAIDEN cannot be properly calibrated if used with short and low-replicated TRW time series (periods shorter than 50 years).

It has also been shown in this study that the inclusion of atmospheric $\mathrm{CO}_{2}$ concentration has a significant impact on the MAIDEN simulations. More generally, MAIDEN appears as a potential good candidate to account for the non-stationarity of the tree-growth-to-climate relationship linked to changing $\mathrm{CO}_{2}$ conditions in paleoclimate reconstructions. In particular, ecophysiological models, such as MAIDEN, could be useful tools to solve the so-called divergence problem in dendroclimatology (D'Arrigo et al. 2008 ). Conversely, from a paleoclimate perspective, not taking into account changing $\mathrm{CO}_{2}$ concentration when using PSMs for data assimilation based reconstructions could lead to inaccurate climate reconstructions. More specifically, models such as VS-Lite could wrongly assign a trend in TRW series due to $\mathrm{CO}_{2}$ concentration changes to the effect of rising temperatures. In turn, this will lead to an overestimation of the climate sensitivity of tree-growth and thus to an overestimation of the amplitude of past reconstructions. However, the impact of $\mathrm{CO}_{2}$ concentration on tree carbon assimilation in more complex ecophysiological models should be evaluated carefully to properly take this process into account.

Consequently, future reconstructions and data assimilation could benefit from the use of complex ecophysiological models such as MAIDEN. Despite the obvious challenges that are associated with the calibration of such models, their potential for improving the quality of the reconstructions makes their complexity worthy. In particular, they widen the range of environments where tree-ring observations can be used for dendroclimatic reconstructions, including regions where the relationship between TRW and climate is more complex. They also account for the potential non-stationarity of tree-growth, for example due to increasing $\mathrm{CO}_{2}$ concentration. Finally, they can prevent from systematic bias in the reconstruction of the climate signal recorded in TRW observations. Additionally, ecophysiological models like MAIDEN are continuously benefiting from improvements made in ecophysiology, in particular in the modelling of the links between climate and tree-growth through complex biological processes. However, in order to optimally use these complex models, we need to (1) have additional site knowledge to properly initialize the model such as data on the root profile, (2) use additional observations to verify specific processes such as phenology and photosynthetic rates, and (3) verify that the tree-ring chronologies are not affected by sampling biases that can distort the growth trends or are linked to non-climatic processes such as tree ontogeny and demographic changes in the sampled stands (Duchesne et al. 2019). Finally, to properly calibrate a complex model such as MAIDEN at the global scale, multiple data information sources should be mixed in the future. For example, tree phenology is hard to set with tree-ring data only. The phenology of MAIDEN could be informed more efficiently using satellite data (e.g. NDVI). On the other hand, simple dendroclimatic models like 
VS-Lite, through their ease of use and calibration, coupled with a satisfying performance in reproducing tree-growth, are also appealing candidates for paleoclimate data assimilation based reconstructions. VS-Lite and MAIDEN thus bring complementary assets for reconstructing past climates. The user must select the model according to the goal of the study (temperature or hydroclimate reconstruction), the data availability at the proxy site and the climate dependence of the TRW observations (one or multiple climate drivers).

More generally, the simultaneous evaluation of tree-growth PSMs of different complexity is essential for any future paleoclimate data assimilation exercises willing to use TRW proxy data and tree-ring PSMs at the global scale. Such study helps to select the adequate PSM and identify the limitations and the advantages of mechanistic modelling in a paleoclimate perspective compared to statistical methods. It is thus a necessary step to increase our ability to robustly reconstruct past climates from tree-rings. In particular, our work sheds light on how process-based dendroclimatic models can improve the skill of reconstructions of past climate from tree-rings in comparison with the commonly used linear reconstruction methods. We have shown that the mechanistic approach has great potential to enhance our understanding of the past climate variability. Consequently, the next step will be to include such models in a data assimilation procedure to reconstruct the climate of the last millennium in regions where the models perform well. On this basis, we will be able to fully evaluate how process-based dendroclimatic models can contribute to the improvement of large-scale reconstructions of past climate variability and justify the added complexity of the procedure compared to linear regressions.

Acknowledgements We gratefully thank François Klein and Marie Cavitte for their comments on the manuscript. JR is F.R.S-FNRS Research Fellow, Belgium (grant no. 1.A841.18); FG received funding by the Quebec Ministry of forests, wildlife and parcs (MFFP; contract number 142332177-D); HG is research director at F.R.S.-FNRS, Belgium; JG is research director at CNRS, France. This publication has received partial funding from Laboratory of Excellence OT-Med (project ANR-11- LABEX-0061, A*MIDEX project 11-IDEX-0001-02). Computational resources have been provided by the supercomputing facilities of the Université catholique de Louvain (CISM/UCL) and the Consortium des Équipements de Calcul Intensif en Fédération Wallonie Bruxelles (CÉCI) funded by the Fond de la Recherche Scientifique de Belgique (F.R.S.-FNRS) under convention 2.5020.11 and by the Walloon Region. We would like to deeply thank the two reviewers and the editor for the careful evaluation of our manuscript and for their constructive comments.

\section{Conflict of interest}

The authors declare that they have no conflict of interest.

\section{References}

Acevedo W, Fallah B, Reich S, Cubasch U (2017) Assimilation of pseudoTree-ring-width observations into an atmospheric general circulation model. Climate of the Past 13(5):545-557, DOI 10.5194/cp-13-545-2017 
Anchukaitis KJ, Wilson R, Briffa KR, Büntgen U, Cook ER, D'Arrigo R, Davi N, Esper J, Frank D, Gunnarson BE, Hegerl G, Helama S, Klesse S, Krusic PJ, Linderholm HW, Myglan V, Osborn TJ, Zhang P, Rydval M, Schneider L, Schurer A, Wiles G, Zorita E (2017) Last millennium Northern Hemisphere summer temperatures from tree rings: Part II, spatially resolved reconstructions. Quaternary Science Reviews 163:1-22, DOI 10.1016/j.quascirev.2017.02.020

Anderson DM, Tardif R, Horlick K, Erb MP, Hakim GJ, Noone D, Perkins WA, Steig E (2019) Additions to the Last Millennium Reanalysis Multi-Proxy Database. Data Science Journal 18(1):2, DOI 10.5334/dsj-2019-002, URL https://datascience.codata.org/article/10.5334/dsj-2019-002/

Babst F, Bodesheim P, Charney N, Friend AD, Girardin MP, Klesse S, Moore DJ, Seftigen K, Björklund J, Bouriaud O, Dawson A, DeRose RJ, Dietze MC, Eckes AH, Enquist B, Frank DC, Mahecha MD, Poulter B, Record S, Trouet V, Turton RH, Zhang Z, Evans ME (2018) When tree rings go global: Challenges and opportunities for retro- and prospective insight. Quaternary Science Reviews 197:1-20, DOI 10.1016/j.quascirev.2018.07.009

Boucher E, Guiot J, Hatté C, Daux V, Danis PA, Dussouillez P (2014) An inverse modeling approach for tree-ring-based climate reconstructions under changing atmospheric $\mathrm{CO}_{2}$ concentrations. Biogeosciences 11(12):32453258, DOI 10.5194/bg-11-3245-2014

Breitenmoser P, Brönnimann S, Frank D (2014) Forward modelling of treering width and comparison with a global network of tree-ring chronologies. Climate of the Past 10(2):437-449, DOI 10.5194/cp-10-437-2014

Briffa KR, Schweingruber FH, Jones PD, Osborn TJ, Harris IC, Shiyatov SG, Vaganov EA, Grudd H (1998) Trees tell of past climates: but are they speaking less clearly today? Philosophical Transactions of the Royal Society of London Series B: Biological Sciences 353(1365):65-73, DOI 10.1098/rstb. 1998.0191, URL https://doi.org/10.1098/rstb.1998.0191

Cook ER, Kairiukstis L (1990) Methods of dendrochronology: Applications in the Environmental Sciences. Kluwer Academic, Boston, DOI 10.1016/ 0048-9697(91)90076-q

Danis PA, Hatté C, Misson L, Guiot J (2012) MAIDENiso: a multiproxy biophysical model of tree-ring width and oxygen and carbon isotopes. Canadian Journal of Forest Research 42(9):1697-1713, DOI 10.1139/x2012-089, URL http://www.nrcresearchpress.com/doi/abs/10.1139/x2012-089

D'Arrigo R, Wilson R, Liepert B, Cherubini P (2008) On the 'Divergence Problem' in Northern Forests: A review of the tree-ring evidence and possible causes. Global and Planetary Change 60(3-4):289-305, DOI 10.1016/ j.gloplacha.2007.03.004

Dee SG, Steiger NJ, Emile-Geay J, Hakim GJ (2016) On the utility of proxy system models for estimating climate states over common era. Journal of Advances in Modeling Earth Systems 8:1164-1179, DOI https://doi.org/10. 1002/2016MS000677

Drew DM, Downes GM, Battaglia M (2010) CAMBIUM, a process-based model of daily xylem development in Eucalyptus. Journal of Theoreti- 
cal Biology 264(2):395-406, DOI 10.1016/j.jtbi.2010.02.013, URL http: $/ / \mathrm{dx}$.doi.org/10.1016/j.jtbi.2010.02.013

Duchesne L, Houle D, Ouimet R, Caldwell L, Gloor M, Brienen R (2019) Large apparent growth increases in boreal forests inferred from tree-rings are an artefact of sampling biases. Scientific Reports 9(1):1-9, DOI 10.1038/ s41598-019-43243-1

Dufrêne E, Davi H, François C, Le Maire G, Le Dantec V, Granier A (2005) Modelling carbon and water cycles in a beech forest. Part I: Model description and uncertainty analysis on modelled NEE. Ecological Modelling 185(2-4):407-436, DOI 10.1016/j.ecolmodel.2005.01.004

Esper J, George SS, Anchukaitis K, D'Arrigo R, Ljungqvist F, Luterbacher J, Schneider L, Stoffel M, Wilson R, Büntgen U (2018) Largescale, millennial-length temperature reconstructions from tree-rings. Dendrochronologia 50:81-90, DOI 10.1016/j.dendro.2018.06.001, URL http: //linkinghub.elsevier.com/retrieve/pii/S1125786518300687

Evans MN, Tolwinski-Ward SE, Thompson DM, Anchukaitis KJ (2013) Applications of proxy system modeling in high resolution paleoclimatology. Quaternary Science Reviews 76:16-28, DOI 10.1016/j.quascirev.2013.05.024, URL http://dx.doi.org/10.1016/j.quascirev.2013.05.024

Fang M, Li X (2019) An Artificial Neural Networks-Based Tree Ring Width Proxy System Model for Paleoclimate Data Assimilation. Journal of Advances in Modeling Earth Systems 11(4):892-904, DOI 10.1029/ 2018MS001525

FAO/IIASA/ISRIC/ISSCAS/JRC (2012) Harmonized World Soil Database (version 1.2). FAO, Rome, Italy and IIASA, Laxenburg, Austria

Farquhar GD, Caemmerer S, Berry JA (1980) A biochemical model of photosynthetic $\mathrm{CO}_{2}$ assimilation in leaves of $\mathrm{C}_{3}$ species. Planta 149(1):78-90-90, URL http://dx.doi .org/10.1007/BF00386231

Fatichi S, Leuzinger S, Körner C (2014) Moving beyond photosynthesis: From carbon source to sink-driven vegetation modeling. New Phytologist 201(4):1086-1095, DOI 10.1111/nph.12614

Fatichi S, Pappas C, Zscheischler J, Leuzinger S (2019) Modelling carbon sources and sinks in terrestrial vegetation. New Phytologist 221(2):652-668, DOI 10.1111/nph.15451

Franke J, Brönnimann S, Bhend J, Brugnara Y (2017) A monthly global paleoreanalysis of the atmosphere from 1600 to 2005 for studying past climatic variations. Scientific Data 4:1-19, DOI 10.1038/sdata.2017.76

Fritts HC (1976) Tree rings and climate. Academic Press, London

Fritts HC (1991) Reconstructing large-scale climatic patterns from tree-ring data: A diagnostic analysis. University of Arizona Press, Tucson, Arizona, USA

Gea-Izquierdo G, Guibal F, Joffre R, Ourcival JM, Simioni G, Guiot J (2015) Modelling the climatic drivers determining photosynthesis and carbon allocation in evergreen Mediterranean forests using multiproxy long time series. Biogeosciences 12(3):2745-2786, DOI 10.5194/bgd-12-2745-2015 
Gea-Izquierdo G, Nicault A, Battipaglia G, Dorado-Liñán I, Gutiérrez E, Ribas M, Guiot J (2017) Risky future for Mediterranean forests unless they undergo extreme carbon fertilization. Global Change Biology 23(7):29152927, DOI 10.1111/gcb.13597, 0608246v3

Gennaretti F, Gea-Izquierdo G, Boucher E, Berninger F, Arseneault D, Guiot $\mathrm{J}$ (2017) Ecophysiological modeling of the climate imprint on photosynthesis and carbon allocation to the tree stem in the North American boreal forest. Biogeosciences 14:4851-4866, DOI 10.5194/bg-2017-51

Giguère-Croteau C, Boucher É, Bergeron Y, Girardin MP, Drobyshev I, Silva LC, Hélie JF, Garneau M (2019) Correction: Plant biology, earth, atmospheric, and planetary sciences (Proceedings of the National Academy of Sciences of the United States of America (2019) 116 (2749-2754) DOI: 10.1073/pnas.1816686116). Proceedings of the National Academy of Sciences of the United States of America 116(10):4748, DOI 10.1073/pnas. 1902083116

Girardin MP, Bouriaud O, Hogg EH, Kurz W, Zimmermann NE, Metsaranta JM, De Jong R, Frank DC, Esper J, Büntgen U, Guo XJ, Bhatti J (2016) No growth stimulation of Canada's boreal forest under half-century of combined warming and $\mathrm{CO}_{2}$ fertilization. Proceedings of the National Academy of Sciences of the United States of America 113(52):E8406-E8414, DOI 10. 1073 pnas. 1610156113

Goosse H, Crespin E, Dubinkina S, Loutre MF, Mann ME, Renssen H, SallazDamaz Y, Shindell D (2012) The role of forcing and internal dynamics in explaining the "Medieval Climate Anomaly". Climate Dynamics 39(12):28472866, DOI 10.1007/s00382-012-1297-0

Guiot J, Torre F, Jolly D, Peyron O, Boreux JJ, Cheddadi R (2000) Inverse vegetation modeling by Monte Carlo sampling to reconstruct palaeoclimates under changed precipitation seasonality and $\mathrm{CO}_{2}$ conditions: Application to glacial climate in Mediterranean region. Ecological Modelling 127(2-3):119140, DOI 10.1016/S0304-3800(99)00219-7

Guiot J, Boucher E, Gea-Izquierdo G (2014) Process models and model-data fusion in dendroecology. Frontiers in Ecology and Evolution 2:1-12, DOI 10. 3389 /fevo.2014.00052, URL http://journal.frontiersin.org/article/ 10.3389/fevo.2014.00052/abstract

Hararuk O, Campbell EM, Antos JA, Parish R (2019) Tree rings provide no evidence of a $\mathrm{CO}_{2}$ fertilization effect in old-growth subalpine forests of western Canada. Global Change Biology 25(4):1222-1234, DOI 10.1111/gcb. 14561

Hartig F, Minunno F, Paul S (2019) BayesianTools: General-Purpose MCMC and SMC Samplers and Tools for Bayesian Statistics. R package version 0.1.6. URL https://github.com/florianhartig/BayesianTools

Hunter JD (2007) Matplotlib: A 2D graphics environment. Computing in Science and Engineering 9(3):90-95, DOI 10.1109/MCSE.2007.55

Jones PD, Briffa KR, Barnett TP, Tett SFB (1998) High-resolution palaeoclimatic records for the last millennium. The Holocene 4:455-471 
Jones PD, Briffa KR, Osborn TJ, Lough JM, Van Ommen TD, Vinther BM, Luterbacher J, Wahl ER, Zwiers FW, Mann ME, Schmidt GA, Ammann CM, Buckley BM, Cobb KM, Esper J, Goosse H, Graham N, Jansen E, Kiefer T, Kull C, Küttel M, Mosley-Thompson E, Overpeck JT, Riedwyl N, Schulz M, Tudhope AW, Villalba R, Wanner H, Wolff E, Xoplaki E (2009) High-resolution palaeoclimatology of the last millennium: A review of current status and future prospects. Holocene 19(1):3-49, DOI 10.1177/ 0959683608098952

Konecky B, McKay N, Churakova (Sidorova) O, Comas-Bru L, Dassié E, DeLong K, Falster G, Fischer M, Jones M, Jonkers L, Kaufman D, Leduc G, Managave S, Martrat B, Opel T, Orsi A, Partin J, Sayani H, Thomas E, Thompson D, Tyler J, Abram N, Atwood A, Conroy J, Kern Z, Porter T, Stevenson S, von Gunten L (2020) The Iso2k Database: A global compilation of paleo- $\delta 18 \mathrm{O}$ and $\delta 2 \mathrm{H}$ records to aid understanding of Common Era climate. Earth System Science Data (12):2261-2288, DOI 10.5194/essd-12-2261-2020 Körner C (2015) Paradigm shift in plant growth control. Current Opinion in Plant Biology 25:107-114, DOI 10.1016/j.pbi.2015.05.003

Körner C, Asshoff R, Bignucolo O, Hättenschwiler S, Keel SG, PeláezRiedl S, Pepin S, Siegwolf RT, Zotz G (2005) Ecology: Carbon flux and growth in mature deciduous forest trees exposed to elevated $\mathrm{CO}_{2}$. Science 309(5739):1360-1362, DOI 10.1126/science.1113977

Lavergne A, Daux V, Villalba R, Barichivich J (2015) Temporal changes in climatic limitation of tree-growth at upper treeline forests: Contrasted responses along the west-to-east humidity gradient in Northern Patagonia. Dendrochronologia 36:49-59, DOI 10.1016/j.dendro.2015.09.001, URL http://dx.doi.org/10.1016/j.dendro.2015.09.001

Lavergne A, Gennaretti F, Risi C, Daux V, Savard M, Naulier M, Villalba R, Begin C, Lavergne A, Gennaretti F, Risi C, Daux V, Boucher E, Lavergne A, Gennaretti F, Risi C, Daux V, Boucher E, Savard MM (2017) Modelling tree ring cellulose $\delta 18 \mathrm{O}$ variations in two temperature-sensitive tree species from North and South America. Climate of the Past (13):1515-1526

Leuning R (1995) A critical appraisal of a combined stomatalphotosynthesis model for $\mathrm{C}_{3}$ plants. Plant, Cell \& Environment 18(4):339355, DOI https://doi.org/10.1111/j.1365-3040.1995.tb00370.x, URL https://onlinelibrary.wiley.com/doi/abs/10.1111/j.1365-3040. 1995.tb00370.x

Lévesque M, Siegwolf R, Saurer M, Eilmann B, Rigling A (2014) Increased water-use efficiency does not lead to enhanced tree growth under xeric and mesic conditions. New Phytologist 203(1):94-109, DOI 10.1111/nph.12772

Mann ME, Bradley RS, Hughes MK (1999) Northern Hemisphere temperatures during the past millennium. Climate Change: Evaluating recent and future climate change 26(6):759-762

Mann ME, Zhang Z, Hughes MK, Bradley RS, Miller SK, Rutherford S, Ni F (2008) Proxy-based reconstructions of hemispheric and global surface temperature variations over the past two millennia. Proceedings of the National Academy of Sciences 105(36):13252-13257, DOI 10.1073/pnas.0805721105 
Mann ME, Zhang Z, Rutherford S, Bradley RS, Hughes MK, Shindell D, Ammann C, Faluvegi G, Ni F (2009) Global Signatures and Dynamical Origins of the Little Ice Age and Medieval Climate Anomaly. Science 326:1256-1260, DOI 10.1126/science.1166349

Marchand W, Girardin MP, Hartmann H, Depardieu C, Isabel N, Gauthier S, Boucher É, Bergeron Y (2020) Strong overestimation of water-use efficiency responses to rising $\mathrm{CO}_{2}$ in tree-ring studies. Global Change Biology 26(8):4538-4558, DOI 10.1111/gcb.15166

Misson L (2004) MAIDEN: a model for analyzing ecosystem processes in dendroecology. Canadian Journal of Forest Research 34(4):874-887, DOI 10.1139/x03-252, URL http://www.nrcresearchpress.com/doi/abs/10. $1139 / \times 03-252$

Myhre G, Shindell D, Bréon FM, Collins W, Fuglestvedt J, Huang J, Koch D, Lamarque JF, Lee D, Mendoza B, Nakajima T, Robock A, Stephens G, Takemura T, Zhang H (2013) Anthropogenic and Natural Radiative Forcing. In: Climate Change 2013: The Physical Science Basis. Contribution of Working Group I to the Fifth Assessment Report of the Intergovernmental Panel on Climate Change, Cambridge University Press, Cambridge, United Kingdom and New York, USA., DOI 10.1017/CBO9781107415324.018

PAGES 2k Consortium (2013) Continental-scale temperature variability during the past two millennia. Nature Geoscience 6(5):339-346, DOI 10.1038/ ngeo1797

PAGES 2k Consortium (2017) A global multiproxy database for temperature reconstructions of the Common Era. Scientific Data 4(170088):1-33, DOI DOI:10.1038/sdata.2017.88

Peñuelas J, Canadell JG, Ogaya R (2011) Increased water-use efficiency during the 20th century did not translate into enhanced tree growth. Global Ecology and Biogeography 20(4):597-608, DOI 10.1111/j.1466-8238.2010.00608.x

Rezsöhazy J, Goosse H, Guiot J, Gennaretti F, Boucher E, André F, Jonard M (2020) Application and evaluation of the dendroclimatic process-based model MAIDEN during the last century in Canada and Europe. Climate of The Past 16:1043-1059, DOI 10.5194/cp-16-1043-2020

Seftigen K, Frank DC, Björklund J, Babst F, Poulter B (2018) The climatic drivers of normalized difference vegetation index and tree-ring-based estimates of forest productivity are spatially coherent but temporally decoupled in Northern Hemispheric forests. Global Ecology and Biogeography 27(11):1352-1365, DOI 10.1111/geb.12802

Sheffield J, Goteti G, Wood EF (2006) Development of a 50-year highresolution global dataset of meteorological forcings for land surface modeling. Journal of Climate 19(13):3088-3111, DOI 10.1175/JCLI3790.1

Silva LC, Anand M, Leithead MD (2010) Recent widespread tree growth decline despite increasing atmospheric $\mathrm{CO}_{2}$. PLoS ONE 5(7), DOI 10.1371/ journal.pone.0011543

St George S, Esper J (2019) Concord and discord among Northern Hemisphere paleotemperature reconstructions from tree rings. Quaternary Science Reviews 203:278-281, DOI S0277379118307170 
Steiger NJ, Smerdon JE (2017) A pseudoproxy assessment of data assimilation for reconstructing the atmosphere-ocean dynamics of hydroclimate extremes. Climate of the Past 13(10):1435-1449, DOI 10.5194/ cp-13-1435-2017

Steiger NJ, Smerdon JE, Cook ER, Cook BI (2018) A reconstruction of global hydroclimate and dynamical variables over the Common Era. Scientific Data 5:1-15, DOI 10.1038/sdata.2018.86

Tardif R, Hakim GJ, Perkins WA, Horlick KA, Erb MP, Emile-Geay J, Anderson DM, Steig EJ, Noone D (2019) Last Millennium Reanalysis with an expanded proxy database and seasonal proxy modeling. Climate of the Past 15(4):1251-1273, DOI 10.5194/cp-15-1251-2019

Tolwinski-Ward SE, Evans MN, Hughes MK, Anchukaitis KJ (2011) An efficient forward model of the climate controls on interannual variation in tree-ring width. Climate Dynamics 36(11-12):2419-2439, DOI 10.1007/ s00382-010-0945-5

Tolwinski-Ward SE, Anchukaitis KJ, Evans MN (2013) Bayesian parameter estimation and interpretation for an intermediate model of tree-ring width. Climate of the Past 9(4):1481-1493, DOI 10.5194/cp-9-1481-2013

Vaganov EA, Hughes MK, Shashkin A (2006) Growth dynamics of conifer tree rings, springer edn. New York

Van Der Sleen P, Groenendijk P, Vlam M, Anten NP, Boom A, Bongers F, Pons TL, Terburg G, Zuidema PA (2015) No growth stimulation of tropical trees by 150 years of $\mathrm{CO}_{2}$ fertilization but water-use efficiency increased. Nature Geoscience 8(1):24-28, DOI 10.1038/ngeo2313

Wilson R, Elling W (2004) Temporal instability in tree-growth/climate response in the Lower Bavarian Forest region: Implications for dendroclimatic reconstruction. Trees - Structure and Function 18(1):19-28, DOI 10.1007/s00468-003-0273-z

Wilson R, D'Arrigo R, Buckley B, Büntgen U, Esper J, Frank D, Luckman B, Payette S, Vose R, Youngblut D (2007) A matter of divergence: Tracking recent warming at hemispheric scales using tree ring data. Journal of Geophysical Research Atmospheres 112(17):1-17, DOI 10.1029/2006JD008318

Wilson R, Anchukaitis K, Briffa KR, Büntgen U, Cook E, D'Arrigo R, Davi N, Esper J, Frank D, Gunnarson B, Hegerl G, Helama S, Klesse S, Krusic PJ, Linderholm HW, Myglan V, Osborn TJ, Rydval M, Schneider L, Schurer A, Wiles G, Zhang P, Zorita E (2016) Last millennium northern hemisphere summer temperatures from tree rings: Part I: The long term context. Quaternary Science Reviews 134:1-18, DOI 10.1016/j.quascirev.2015.12.005 


\section{S1 Supplementary materials}

Table S1 Main constants linked to site conditions and control parameters in the MAIDEN model.

\begin{tabular}{l|l|l}
\hline Parameter & Meaning & Units \\
\hline exp_site & $\begin{array}{l}\text { Indicates if the species at the } \\
\text { site is a deciduous (1) or ever- } \\
\text { green (2) tree }\end{array}$ & no unit (1 or 2) \\
base_elev_cst & $\begin{array}{l}\text { Station elevation } \\
\text { Station isohyet }\end{array}$ & meters \\
base_isoh_cst & Site latitude & degrees \\
site_lat_cst & Site elevation & meters \\
site_elev_cst & Site slope & degrees \\
site_slp_cst & Site aspect & degrees \\
site_asp_cst & Site isohyet & centimeters \\
site_isoh_cst & Site East slope & degrees \\
site_ehoriz_cst & Site West slope & degrees \\
site_whoriz_cst & Soil layer thickness & meters \\
thick1-2-3 or 4 & \% of fine roots in the soil layer & Coeff. between 0-1 \\
finefrac1-2-3 or 4 & $\%$ of clay in the soil layer & $\%$ \\
clay1-2-3 or 4 & \% of sand in the soil layer & $\%$ \\
sand1-2-3 or 4 & \multicolumn{2}{|l}{} \\
\hline
\end{tabular}


Table S2 Calibrated parameters of the MAIDEN model Gennaretti et al. 2017).

\begin{tabular}{|c|c|c|c|c|}
\hline & Process & & Parameter & Units \\
\hline \multirow[t]{6}{*}{ Photosynthesis } & $\begin{array}{l}\text { Temperature dependence of photosyn- } \\
\text { thesis }\end{array}$ & Asymptote & $V_{\max }$ & $\begin{array}{l}\mu \mathrm{mol} \quad \mathrm{C} \cdot \mathrm{m}^{-2} \text { of } \\
\text { leaves } \cdot \mathrm{s}^{-1}\end{array}$ \\
\hline & & Slope & $V_{b}$ & ${ }^{\circ} \mathrm{C}^{-1}$ \\
\hline & & Inflection point & $V_{i p}$ & ${ }^{\circ} \mathrm{C}$ \\
\hline & $\begin{array}{l}\text { Water stress dependence of stomatal } \\
\text { conductance }\end{array}$ & Slope & $\operatorname{soil}_{b}$ & $\mathrm{~mm}^{-1}$ \\
\hline & & Inflection point & soil $_{i p}$ & $\mathrm{~mm}$ \\
\hline & $\begin{array}{l}\text { Acclimation to temperature of photo- } \\
\text { synthesis }\end{array}$ & Needed days & $\tau$ & days \\
\hline \multirow[t]{12}{*}{$\begin{array}{l}\text { Carbon } \\
\text { tion }\end{array}$} & $\begin{array}{l}\text { Definition of canopy maximum amount } \\
\text { of carbon }\end{array}$ & $\begin{array}{l}\text { Slope of temperature depen- } \\
\text { dence }\end{array}$ & Canopy $T$ & ${ }^{\circ} \mathrm{C}^{-1}$ \\
\hline & & $\begin{array}{l}\text { Slope of precipitation depen- } \\
\text { dence }\end{array}$ & CanopyP & $\mathrm{mm}^{-1}$ \\
\hline & Start of the growing season (budburst) & GDD sum threshold & $G D D_{1}$ & ${ }^{\circ} \mathrm{C}$ \\
\hline & & Day before the later start & vegphase23 & day of the year \\
\hline & & $\begin{array}{l}\text { Acclimation to changing GDD } \\
\text { sums }\end{array}$ & day23_flex & years \\
\hline & $\begin{array}{l}\text { Daily available carbon from buds reser- } \\
\text { voir }\end{array}$ & Storage $\mathrm{C}$ used by the tree & $C_{b u d}$ & $\begin{array}{l}\text { gC. } \mathrm{m}^{-2} \text { of stand . } \\
\text { day }^{-1}\end{array}$ \\
\hline & $\begin{array}{l}\text { Partition of carbon to different tree } \\
\text { compartments during growing season }\end{array}$ & $\begin{array}{l}\text { Portion allocated to canopy } \\
\text { and roots }\end{array}$ & $h 3$ & fraction $(0-1)$ \\
\hline & $\begin{array}{l}\text { Partition of carbon to different tree } \\
\text { compartments during summer period }\end{array}$ & $\begin{array}{l}\text { Inflection point of the temper- } \\
\text { ature dependence }\end{array}$ & $s t_{4 t e m p}$ & ${ }^{\circ} \mathrm{C}$ \\
\hline & $\begin{array}{l}\text { Photoperiod for transition from sum- } \\
\text { mer to fall season }\end{array}$ & Photoperiod threshold & photoper & hours \\
\hline & $\begin{array}{l}\text { Carbon losses from the canopy (ever- } \\
\text { green only) }\end{array}$ & Yearly canopy turnover rate & PercentFall & fraction $(0-1)$ \\
\hline & & $\begin{array}{l}\text { Approximate day of the year } \\
\text { with maximum losses }\end{array}$ & OutMax & day of the year \\
\hline & & $\begin{array}{l}\text { Index proportional to the } \\
\text { length of the period with } \\
\text { losses }\end{array}$ & OutLength & NA \\
\hline
\end{tabular}


Table S3 Calibrated parameters of the MAIDEN model (Gea-Izquierdo et al. 2015).

\begin{tabular}{|c|c|c|c|c|}
\hline & Process & & Parameter & Units \\
\hline \multirow[t]{5}{*}{ Photosynthesis } & Temperature dependence of photosyn- & Asymptote & & $\mu \mathrm{mol} \quad \mathrm{C} \cdot \mathrm{m}^{-2}$ of \\
\hline & & Slope & $V_{b}$ & ${ }^{\circ} \mathrm{C}^{-1}$ \\
\hline & & Inflection point & $V_{i p}$ & ${ }^{\circ} \mathrm{C}$ \\
\hline & $\begin{array}{l}\text { Water stress dependence of stomatal } \\
\text { conductance }\end{array}$ & Slope & soil $_{b}$ & $\mathrm{~mm}^{-1}$ \\
\hline & & Inflection point & soil $_{i p}$ & $\mathrm{~mm}$ \\
\hline \multirow[t]{11}{*}{$\begin{array}{l}\text { Carbon } \\
\text { tion }\end{array}$} & $\begin{array}{l}\text { Definition of canopy maximum amount } \\
\text { of carbon }\end{array}$ & $\begin{array}{l}\text { Slope of temperature depen- } \\
\text { dence }\end{array}$ & $\operatorname{perc}_{L A I}$ & ${ }^{\circ} \mathrm{C}^{-1}$ \\
\hline & Start of the growing season (budburst) & GDD sum threshold & $G D D_{1}$ & ${ }^{\circ} \mathrm{C}$ \\
\hline & & Day before the later start & vegphase23 & day of the year \\
\hline & $\begin{array}{l}\text { Daily available carbon from buds reser- } \\
\text { voir }\end{array}$ & Storage $\mathrm{C}$ used by the tree & $C_{b u d}$ & $\begin{array}{l}\text { gC. } m^{-2} \text { of stand } \\
\text { day }^{-1}\end{array}$ \\
\hline & $\begin{array}{l}\text { Partition of carbon to different tree } \\
\text { compartments during growing season }\end{array}$ & $\begin{array}{l}\text { Definition of carbon allocated } \\
\text { to the stem as a function of soil } \\
\text { water }\end{array}$ & $p_{3 m o i s t}$ & $\mathrm{~mm}^{-1}$ \\
\hline & & $\begin{array}{l}\text { Definition of carbon allocated } \\
\text { to the stem as a function of } \\
\text { maximum temperature }\end{array}$ & $p_{3 t e m p}$ & ${ }^{\circ} \mathrm{C}$ \\
\hline & & $\begin{array}{l}\text { Definition of carbon allocated } \\
\text { to the stem as a function of soil } \\
\text { water }\end{array}$ & $\begin{array}{c}p_{3 s d} \\
s t_{3 m o i s t}\end{array}$ & ${ }^{\circ} \mathrm{C}$ \\
\hline & & $\begin{array}{l}\text { Definition of carbon allocated } \\
\text { to the stem as a function of } \\
\text { maximum temperature }\end{array}$ & st 3 temp & ${ }^{\circ} \mathrm{C}$ \\
\hline & $\begin{array}{l}\text { Partition of carbon to different tree } \\
\text { compartments during summer period }\end{array}$ & $\begin{array}{l}\text { Definition of carbon allocated } \\
\text { to stem or storage as a function } \\
\text { of maximum temperature }\end{array}$ & $\begin{array}{l}s t_{3 s d} \text { temp } \\
\text { st } t_{4 t e m p}\end{array}$ & $\begin{array}{l}{ }^{\circ} \mathrm{C} \\
{ }^{\circ} \mathrm{C}^{-1}\end{array}$ \\
\hline & & $\begin{array}{l}\text { Definition of carbon allocated } \\
\text { to stem or storage as a function } \\
\text { of soil water }\end{array}$ & $s t_{4 s d_{-} \text {moist }}$ & $\mathrm{mm}$ \\
\hline & $\begin{array}{l}\text { Photoperiod for transition from sum- } \\
\text { mer to fall season }\end{array}$ & Photoperiod threshold & photoper & hours \\
\hline
\end{tabular}


Table S4 Ranges of calibrated parameters prior uniform distributions, for the MAIDEN model (Gennaretti et al. 2017). See Table S2 for details on calibrated parameters.

\begin{tabular}{|c|c|c|c|}
\hline & Parameter & Lower bound & Upper bound \\
\hline \multirow[t]{6}{*}{ Photosynthesis } & $V_{\max }$ & 5 & 150 \\
\hline & $V_{b}$ & -0.3 & -0.05 \\
\hline & $V_{i p}$ & 5 & 30 \\
\hline & soil $_{b}$ & -0.06 & -0.005 \\
\hline & soil $_{i p}$ & 3 & 400 \\
\hline & $\tau$ & 1 & 20 \\
\hline \multirow{12}{*}{$\begin{array}{l}\text { Carbon } \\
\text { tion }\end{array}$} & CanopyT & 0 & 20 \\
\hline & CanopyP & 0 & 20 \\
\hline & $G D D_{1}$ & 10 & 250 \\
\hline & vegphase23 & 90 & 190 \\
\hline & day23_flex & 1 & 10 \\
\hline & $C_{b u d}$ & 1 & 16 \\
\hline & h3 & 0 & 1 \\
\hline & $s t_{4 t e m p}$ & 1 & 100 \\
\hline & photoper & 9 & 14 \\
\hline & PercentFall & 0.09 & 0.5 \\
\hline & OutMax & 120 & 250 \\
\hline & OutLength & 2 & 15 \\
\hline
\end{tabular}


Table S5 Ranges of calibrated parameters prior uniform distributions, for the MAIDEN model (Gea-Izquierdo et al. 2015). See Table S3 for details on calibrated parameters.

\begin{tabular}{|c|c|c|c|}
\hline & Parameter & Lower bound & Upper bound \\
\hline \multirow[t]{5}{*}{ Photosynthesis } & $V_{\max }$ & 5 & 150 \\
\hline & $V_{b}$ & -0.3 & -0.05 \\
\hline & $V_{i p}$ & 5 & 30 \\
\hline & soil $_{b}$ & -0.06 & -0.005 \\
\hline & soil $_{i p}$ & 3 & 400 \\
\hline \multirow{13}{*}{$\begin{array}{l}\text { Carbon } \\
\text { tion }\end{array}$} & $\operatorname{perc}_{L A I}$ & 40 & 250 \\
\hline & $G D D_{1}$ & 10 & 250 \\
\hline & vegphase23 & 90 & 190 \\
\hline & $C_{b u d}$ & 1 & 16 \\
\hline & $p_{3 m o i s t}$ & -0.7 & -0.001 \\
\hline & $p_{3 t e m p}$ & -160 & 185 \\
\hline & $p_{3 s d}$ & 5 & 200 \\
\hline & $s_{3 m o i s t}$ & -0.8 & -0.005 \\
\hline & $s t_{3 t e m p}$ & -170 & 230 \\
\hline & $s t_{3 s d \_t e m p}$ & 5 & 300 \\
\hline & $s \bar{t}_{4 t e m p}$ & 0.008 & 0.95 \\
\hline & $s t_{4 s d_{-} m o i s t}$ & 45 & 1090 \\
\hline & photoper & 9 & 14 \\
\hline
\end{tabular}

Table S6 Pearson correlations between different climate indicators and MAIDEN or VSLite verification correlations (1901-1949). O-S stands for the year starting from October (previous year) to September (current year); P for precipitation; JAS for July-AugustSeptember; $\mathrm{T}$ for temperature. Asterisks stand for significant correlations (p-value $<0.05)$. The difference in the number of sites on which correlations are computed is due to the phenological criterion that has been applied to MAIDEN calibrated sites (see Sect. 2.4.1 for more details).

\begin{tabular}{lc}
\hline Model (version) & Correlation \\
\hline Correlations between O-S mean cumulative P correlation and verification correlation & 0.073 \\
MAIDEN (Ge2017; 189 sites) & 0.076 \\
MAIDEN (GI2015; 160 sites) & -0.067 \\
VS-Lite (302 sites) & 0.036 \\
Correlations between annual mean T correlation and verification correlation & 0.036 \\
MAIDEN (Ge2017; 189 sites) & -0.052 \\
MAIDEN (GI2015; 160 sites) & 0.027 \\
VS-Lite (302 sites) & 0.049 \\
Correlations between JAS mean T correlation and verification correlation & -0.053 \\
MAIDEN (Ge2017; 189 sites) & \\
MAIDEN (GI2015; 160 sites) & \\
VS-Lite (302 sites) &
\end{tabular}


Table S7 Pearson correlations between correlations of observed TRW with different climate indicators and MAIDEN or VS-Lite verification correlations (1901-1949). O-S stands for the year starting from October (previous year) to September (current year); P for precipitation; JAS for July-August-September; T for temperature. Asterisks stand for significant correlations ( $p$-value $<0.05$ ). The difference in the number of sites on which correlations are computed is due to the phenological criterion that has been applied to MAIDEN calibrated sites (see Sect. 2.4.1 for more details).

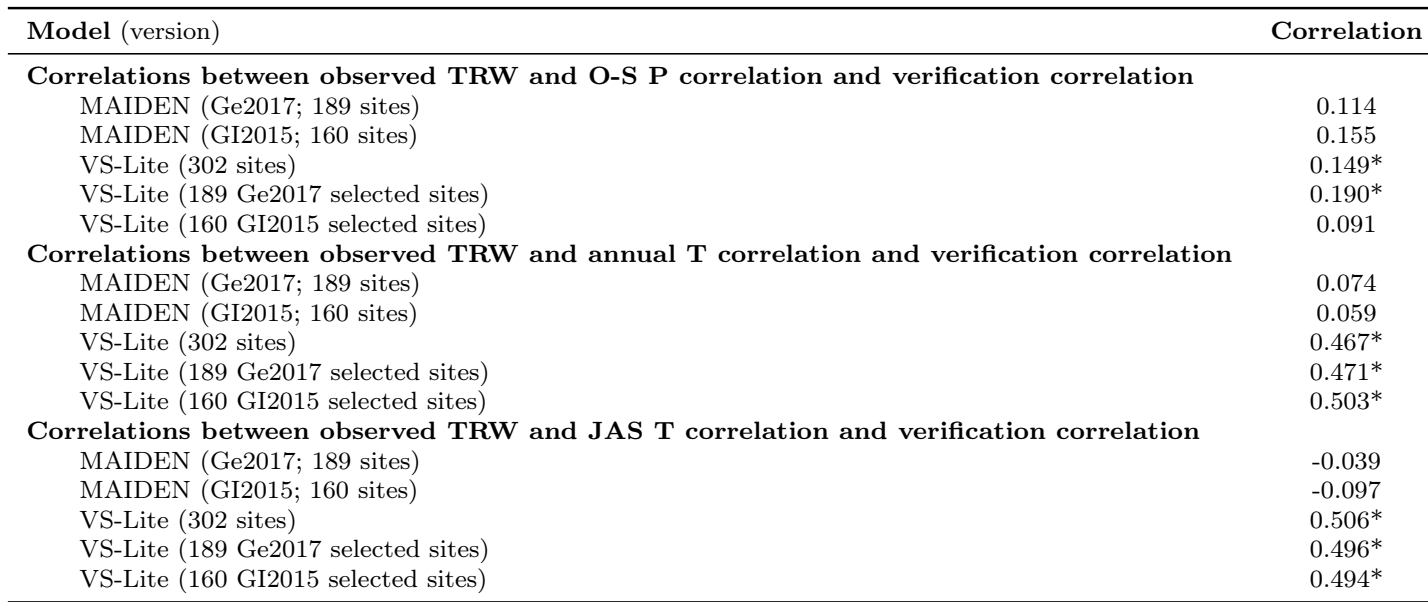


Table S8 Pearson correlations of correlations between different climate indicators and treering width observations with correlations between the same climate indicators and MAIDEN or VS-Lite tree-growth simulations (1901-1949 verification period). O-S stands for the year starting from October (previous year) to September (current year); P for precipitation; JAS for July-August-September; T for temperature; TRindex for tree-ring index. Asterisks stand for significant correlations ( $\mathrm{p}$-value $<0.05$ ). The difference in the number of sites on which correlations are computed is due to the phenological criterion that has been applied to MAIDEN calibrated sites (see Sect.2.4.1 for more details).

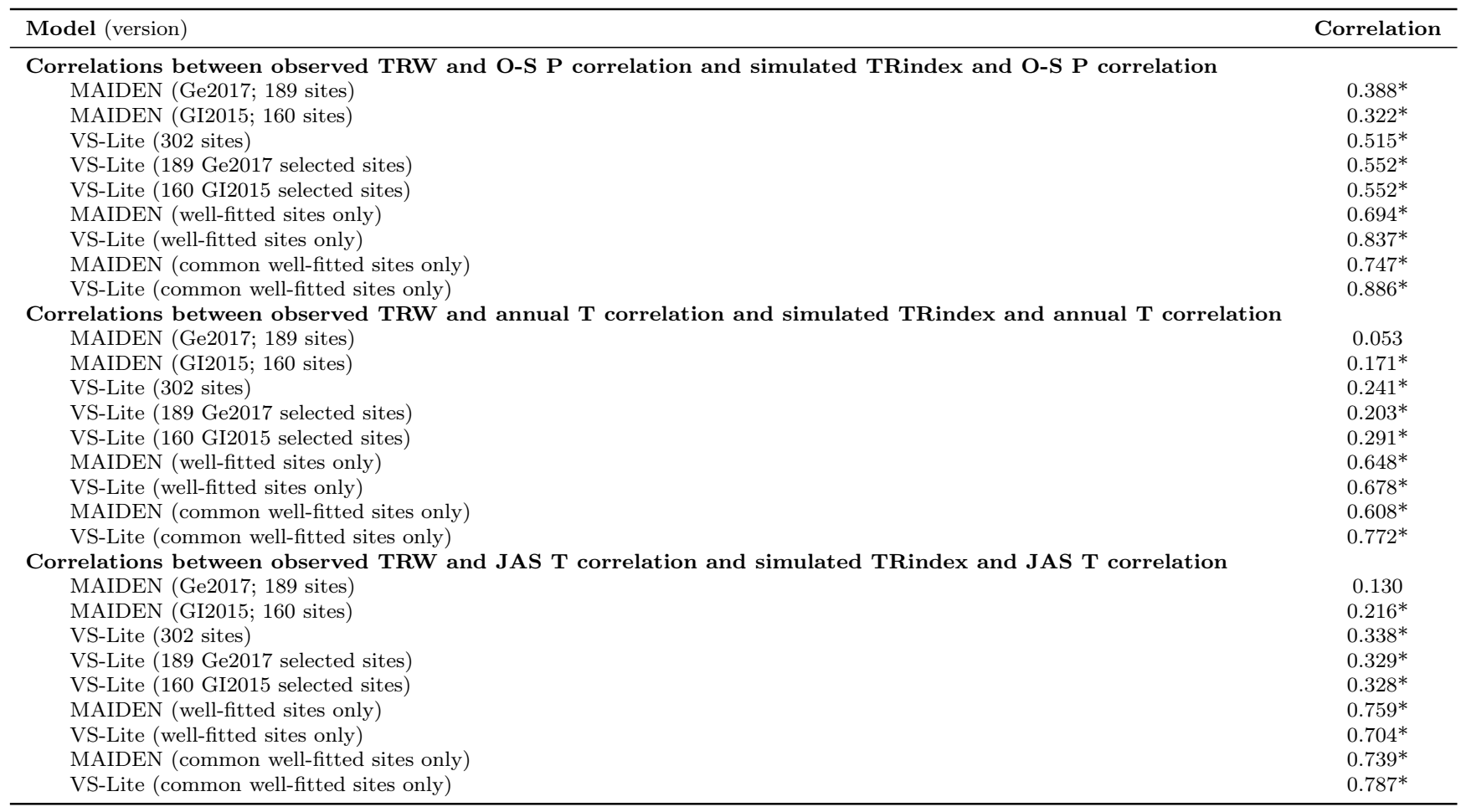




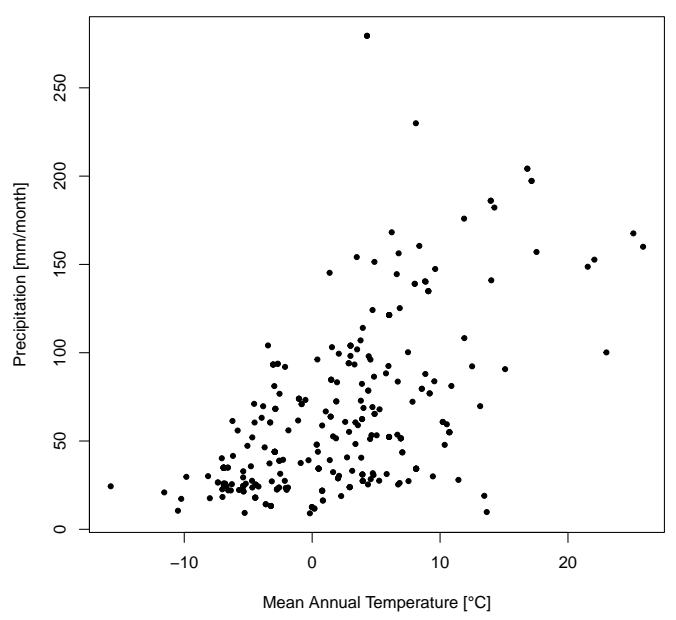

Fig. S1 Mean monthly cumulative precipitation (in millimeters per month) as a function of mean annual temperature $\left(\right.$ in $^{\circ} \mathrm{C}$ ) at the 302 PAGES2k TRW sites used in this study. The climate data are from the Global Meteorological Forcing Dataset for land surface modelling (v2) at $0.5^{\circ}$ resolution (Section 2.3 over the 1901-2000 time period.

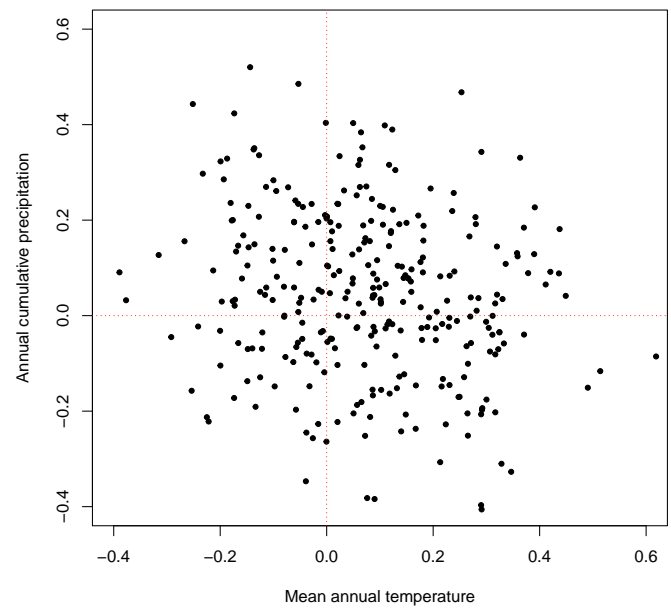

Fig. S2 Correlations between annual cumulative precipitation and TRW observations as a function of correlations between mean annual temperature and TRW observations at the 302 PAGES2k TRW sites used in this study, over the 1901-2000 period. The climate data are from the Global Meteorological Forcing Dataset for land surface modelling (v2) at $0.5^{\circ}$ resolution (Section 2.3. 


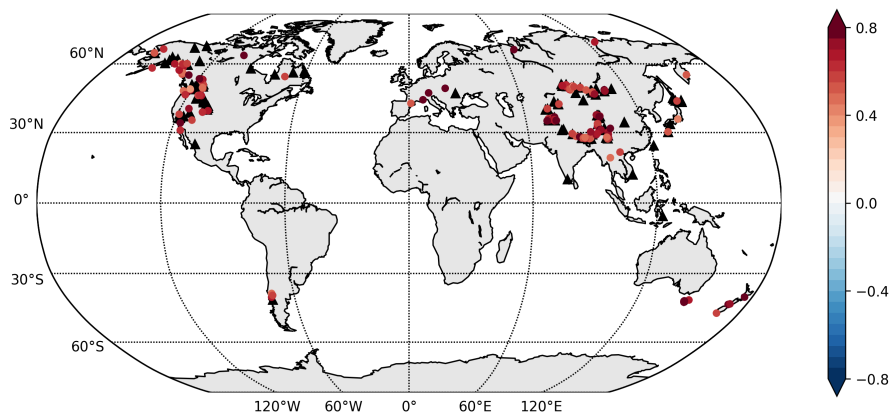

Fig. S3 MAIDEN (Gea-Izquierdo et al. 2015) calibration correlations for selected sites (Sect. 2.4.1 160 sites out of 302). Background map from Hunter (2007).

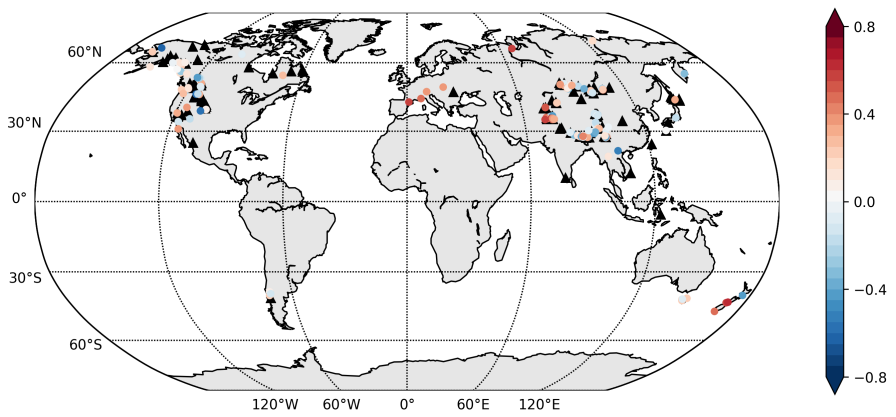

Fig. S4 MAIDEN (Gea-Izquierdo et al. 2015) verification correlations for selected sites (Sect. 2.4.1 160 sites out of 302). Background map from Hunter (2007).

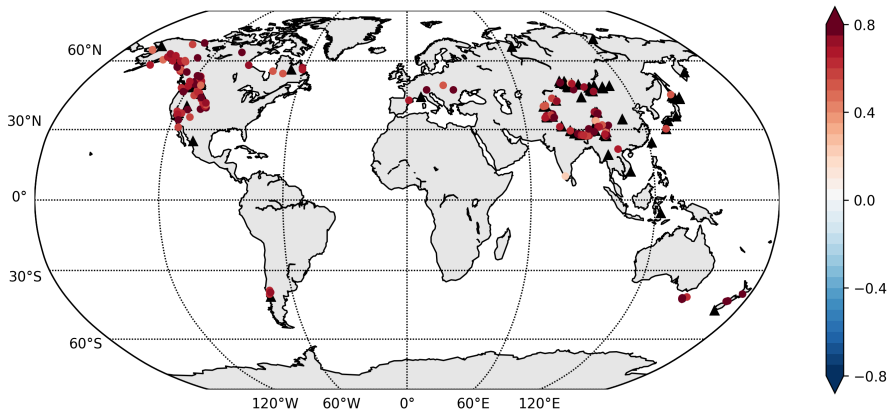

Fig. S5 MAIDEN (Gennaretti et al. 2017) calibration correlations for selected sites (Sect. 2.4.1 189 sites out of 302). Background map from Hunter (2007). 


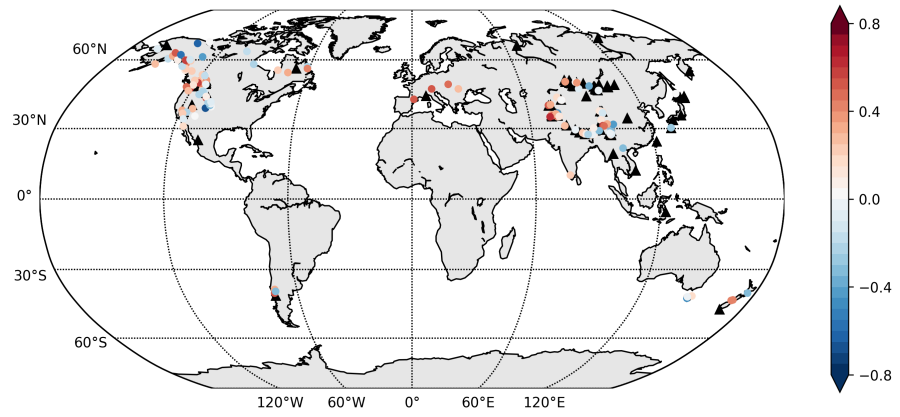

Fig. S6 MAIDEN Gennaretti et al. 2017) verification correlations for selected sites (Sect.2.4.1 189 sites out of 302). Background map from Hunter (2007).

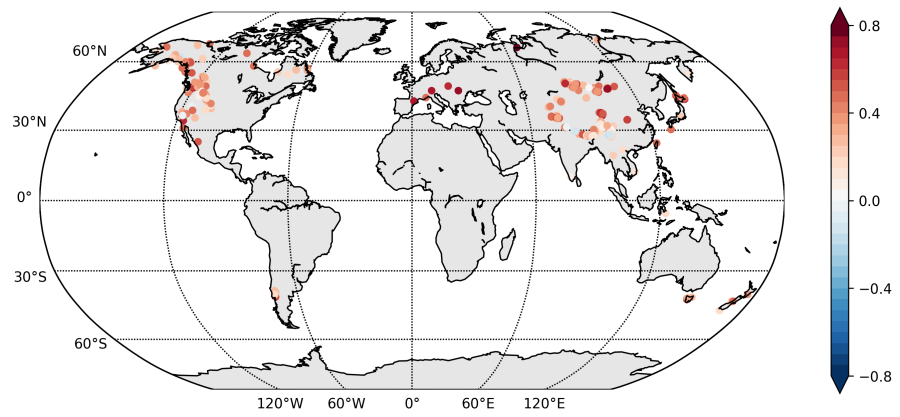

Fig. S7 VS-Lite calibration correlations for 302 sites. Background map from Hunter (2007).

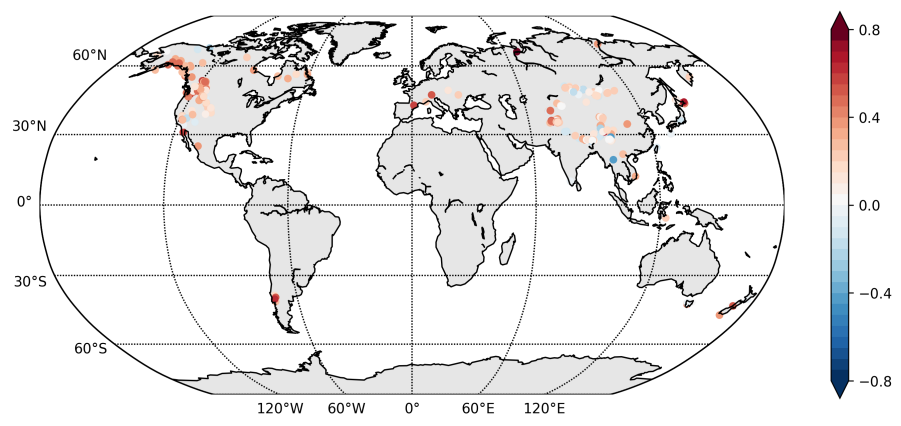

Fig. S8 VS-Lite verification correlations for 302 sites. Background map from Hunter (2007). 


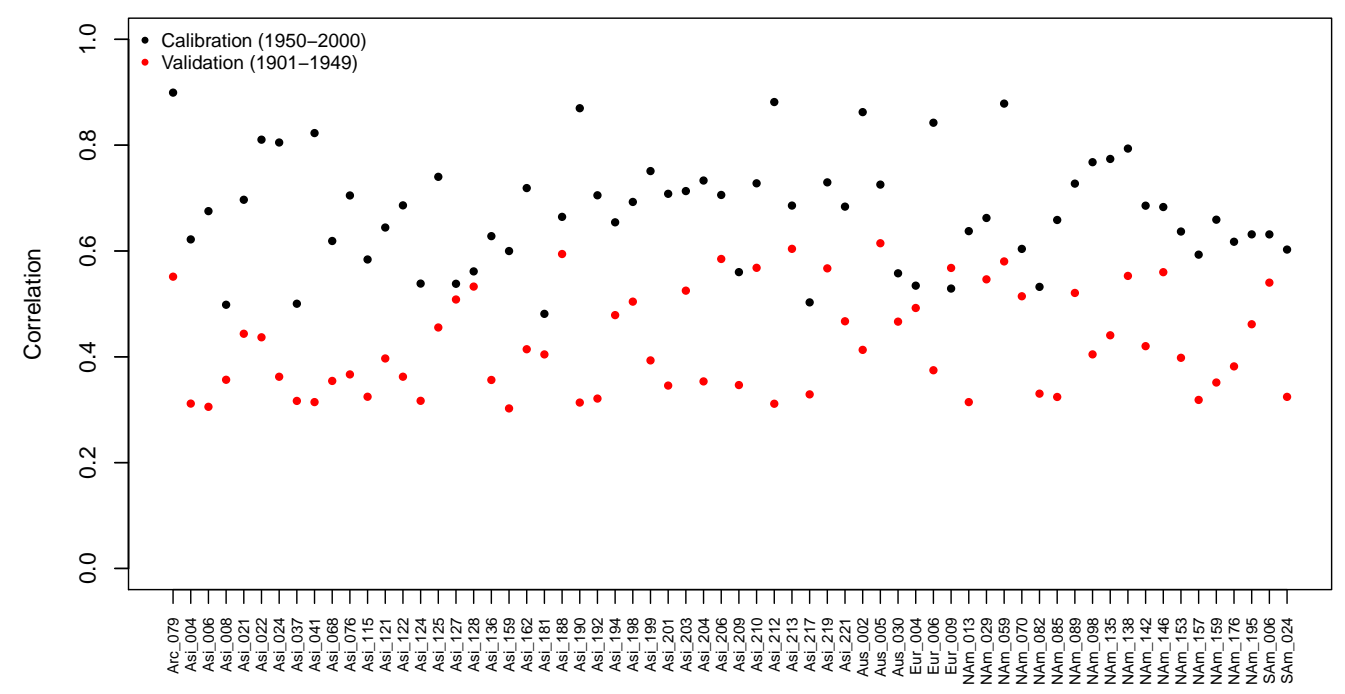

(a) MAIDEN

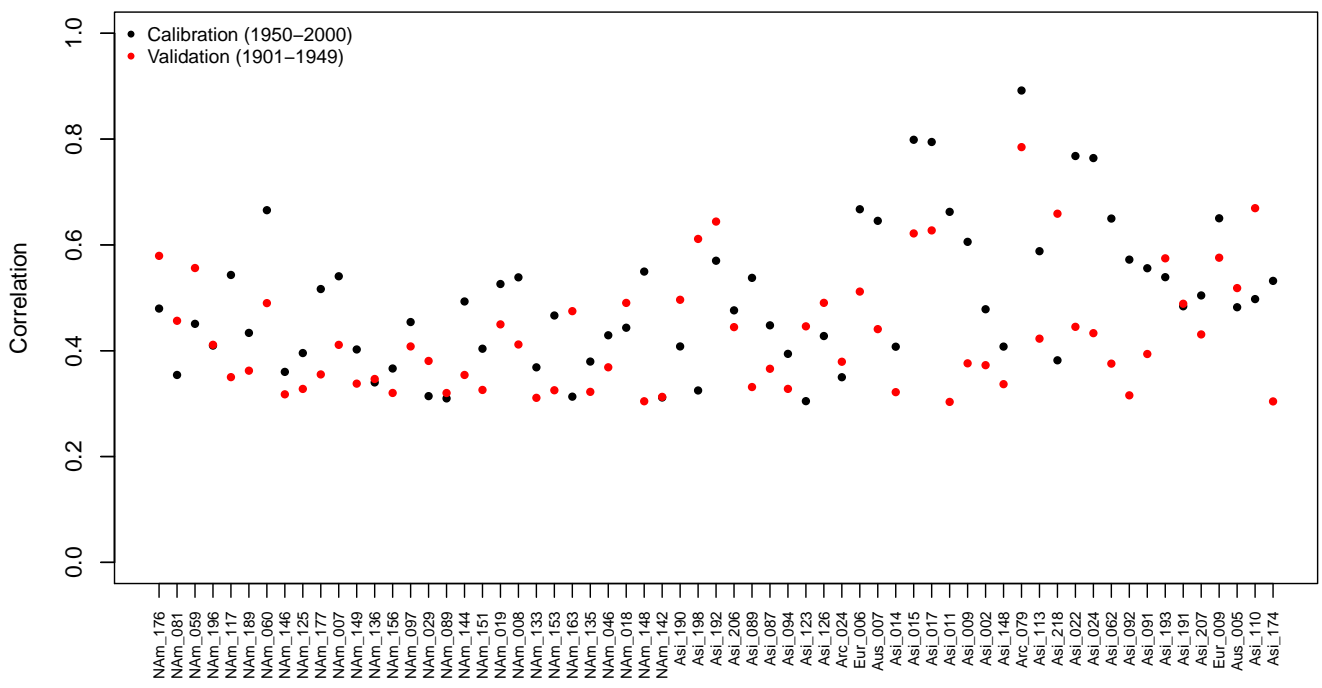

(b) VS-Lite

Fig. S9 (a) MAIDEN (64 sites) and (b) VS-Lite (63 sites) calibration (1950-2000) and verification (1901-1949) correlations (all significant at the 95\% confidence level) for wellfitted sites (Sect. 3.1) (with names from the PAGES2k database: $N A m$ for North American sites; Asi for Asian sites; Eur for European sites; Arc for Arctic sites; Aus for Australian, Tasmanian or New Zealand sites; $S A m$ for South American sites). 


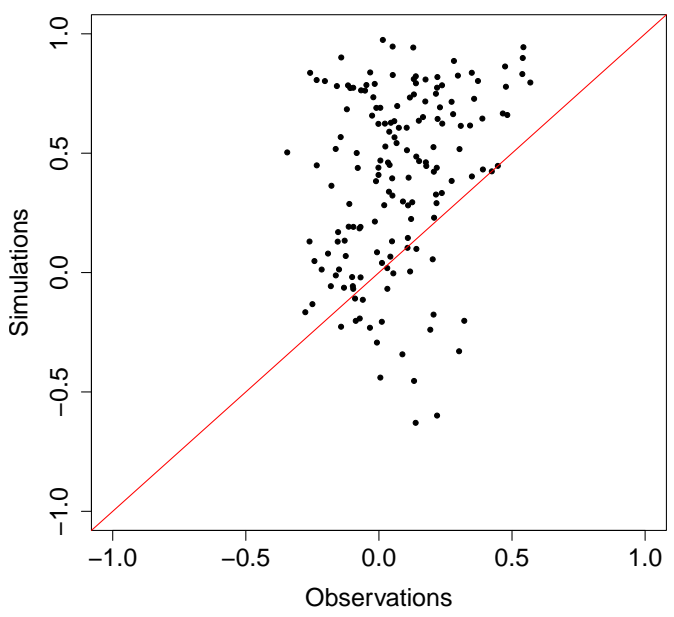

Fig. S10 Correlations between mean annual temperature and VS-Lite tree-ring index simulations as a function of correlations between mean annual temperature and TRW observations for MAIDEN (Gea-Izquierdo et al. 2015) selected sites (Sect. 2.4.1 160 sites out of 302), over the 1901-1949 verification period.

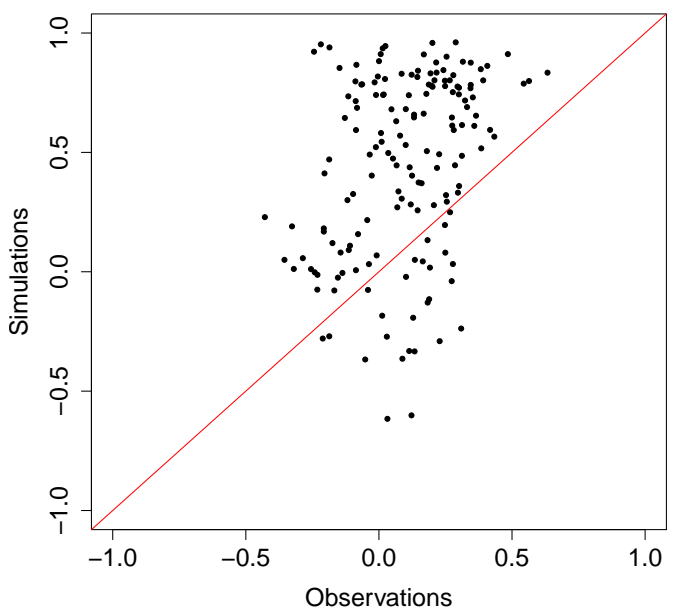

Fig. S11 Correlations between mean July-August-September temperature and VS-Lite tree-ring index simulations as a function of correlations between mean July-AugustSeptember temperature and TRW observations for MAIDEN (Gea-Izquierdo et al., 2015) selected sites (Sect. 2.4.1 160 sites out of 302), over the 1901-1949 verification period. 


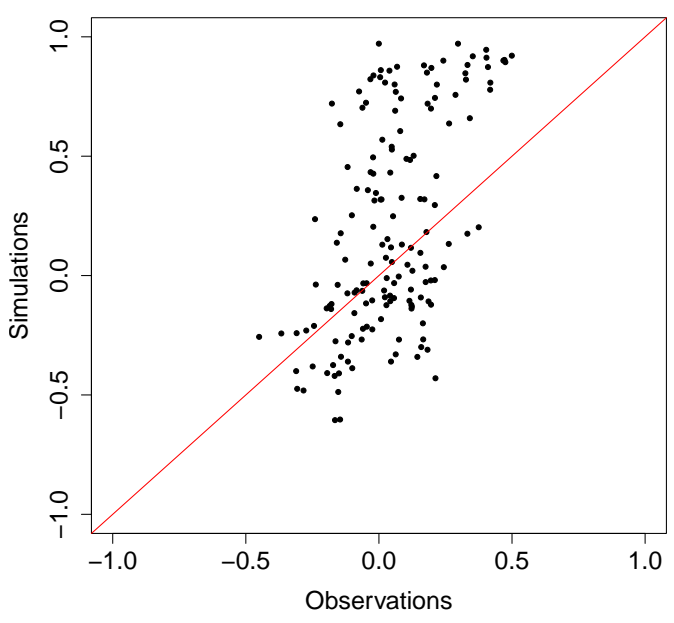

Fig. S12 Correlations between October-September cumulative precipitation and VS-Lite tree-ring index simulations as a function of correlations between October-September cumulative precipitation and TRW observations for MAIDEN (Gea-Izquierdo et al., 2015) selected sites (Sect. 2.4.1 160 out of 302), over the 1901-1949 verification period.

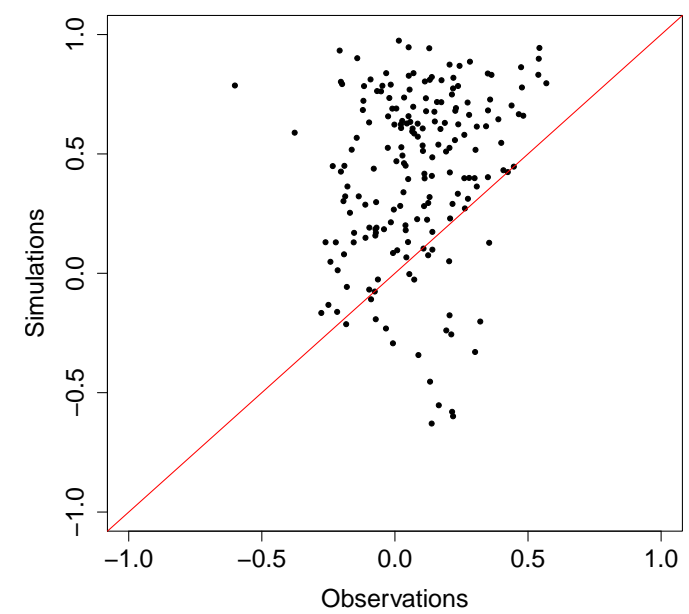

Fig. S13 Correlations between mean annual temperature and VS-Lite tree-ring index simulations as a function of correlations between mean annual temperature and TRW observations for MAIDEN (Gennaretti et al. 2017) selected sites (Sect.2.4.1. 189 sites out of 302), over the 1901-1949 verification period 


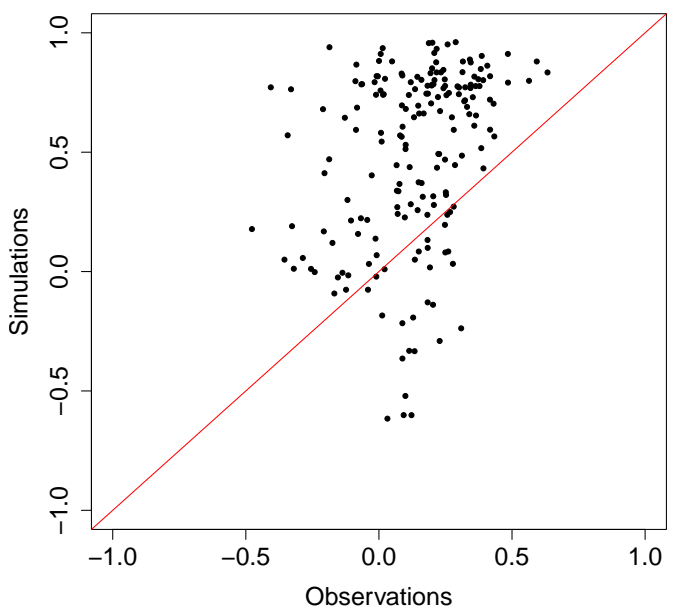

Fig. S14 Correlations between mean July-August-September temperature and VS-Lite tree-ring index simulations as a function of correlations between mean July-AugustSeptember temperature and TRW observations for MAIDEN (Gennaretti et al., 2017) selected sites (Sect. 2.4.1 189 sites out of 302), over the 1901-1949 verification period.

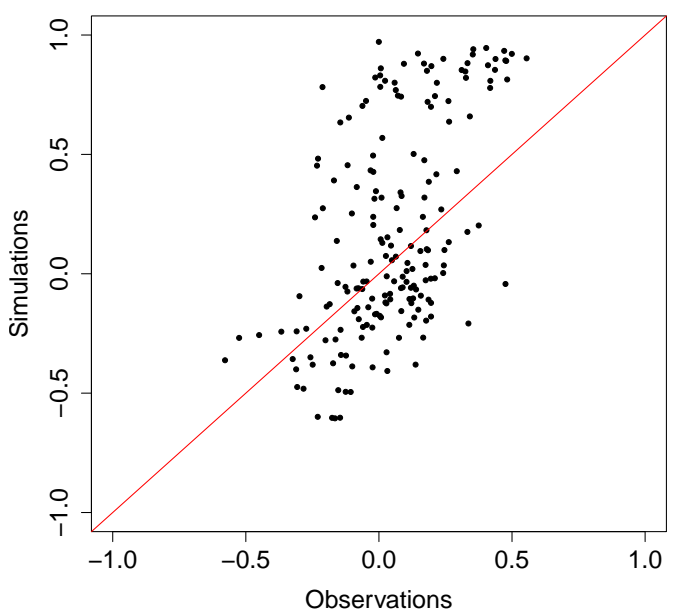

Fig. S15 Correlations between October-September cumulative precipitation and VS-Lite tree-ring index simulations as a function of correlations between October-September cumulative precipitation and TRW observations for MAIDEN (Gennaretti et al. 2017) selected sites (Sect.2.4.1 189 out of 302), over the 1901-1949 verification period. 